\title{
EL LARGO CAMINO JURÍDICO Y POLÍTICO HACIA EL PLAN BAKER II. ¿ESTACIÓN DE TÉRMINO?*
}

\author{
Carlos RuIZ MigueL**
}

RESUMEN: En pocos casos se aprecia mejor la tensión entre el "derecho" y la "política" como en el conflicto del Sahara Occidental. El derecho aplicable al caso se mantiene prácticamente sin variación, desde que España, entonces potencia administradora, inscribió al Sahara Occidental como "territorio no autónomo" en Naciones Unidas. Desde entonces, los diversos órganos de la ONU han mantenido invariable la doctrina, según la cual estamos ante una colonia que no forma parte de la "integridad territorial" de otro Estado, y que por tanto debe descolonizarse por un referéndum de autodeterminación. El llamado Plan Baker II, avalado por las resoluciones 1495 y 1541 del Consejo de Seguridad, constituye el último intento en el que es posible una solución "política" que no vulnere al derecho internacional.

ABSTRACT: There are few cases where the tension between the "law" and "politics" can be perceived as well as in the Western Sahara. The law applied to the case has remained practically intact since Spain, the former power, declared Western Sahara as a "non autonomous territory" within the United Nations. Since then, the various UN agencies have maintained intact the doctrine that reads that we are before a colony that does not belong to the "territorial integrity" of another State, and that therefore, shall be decolonized by means of a self determination referendum. The so called Baker Plan II backed up by Security Council resolutions 1495 and 1541 represents the last pole in which a political solution that does not harm International "Law" is possible.

RÉSUMÉ: Il y a peu de cas où on peut mieux apprecier la tension existante entre "le droit" et "la politique" que le conflict du Sahara de l'Ouest. Le Droit applicable au cas se mantient invariable depuis que la puissance administratice de l'époque -Espagneinscrît aux Nations Unies le dit territoire de Sahara de l'Ouest comme "territoire no autonome" aux Nations Unies. Jusqu'à ce moment là, les plusieurs organismes de l'Organisation ont mantenue invariable la doctrine sostenant qu'il s'agit d'une colonie qui ne fait partie de "l'integrité territorial" d'un autre Etat et que, par conséquent, elle doit être décolonisée à travers d'un référendum d'autodetermination. Le dit Plan Baker II avalisé par les résolutions 1495 y 1541 del Conseil de Sécurité, représent le dernier extrême où une solution "politique" qui ne viole pas "le Droit" International, soit possible.

* Este artículo es una actualización y revisión del trabajo homónimo publicado por el Real Instituto Elcano de Estudios Internacionales y Estratégicos, como Documento de Trabajo/Working Paper 2003/19 (Madrid, 13 de octubre de 2003), 33 pp. De aquella primera versión existe una traducción francesa de Martine de Froberville [http://arso.org.site.voila.fr/CRM131003.html] y una traducción árabe [http://www.creima.net/plan\%20issues2.htm].

** Catedrático de derecho constitucional de la Universidad de Santiago de Compostela. 
SUMARIO: I. Introducción. II. Un largo conflicto jurídico, ya solucionado. III. Los intentos de desvirtuar el derecho internacional. Títulos viciados, política de hechos consumados y guerra. IV. El bloqueo de las soluciones jurídicas y políticas. El intento de compromiso entre lo jurídico y lo político. El Plan de Paz y los Acuerdos de Houston. V. Los intentos de Marruecos de aprovechar su ventaja para buscar una "solución política" al margen del derecho, pero avalada por él mismo. El Plan Baker I. VI. Las vías de solución abortadas. La administración directa por Naciones Unidas y la partición. VII. El fracaso del intento de eximirse del derecho internacional y la propuesta de solución de compromiso teóricamente favorable a Marruecos. El Plan Baker II. VIII. El rechazo marroqui al Plan Baker. IX. El reforzamiento del derecho saharaui y el nuevo intento marroqui de eludir el derecho internacional mediante un nuevo "acuerdo político" cuatripartito.

X. Perspectivas. XI. Conclusiones.

\section{INTRODUCCIÓN}

Una de las más llamativas singularidades del conflicto sobre la última colonia africana, el Sahara Occidental, reside en la persistente tensión que se produce en el mismo entre el "derecho" y la "política": por un lado, existen pronunciamientos jurídico-internacionales terminantes cuya puesta en práctica solucionaría de modo inmediato y sencillo esta ya larga disputa; por otro, encontramos innumerables maniobras políticas dirigidas a enervar la eficacia de las reglas jurídicas. El Plan Baker II es hasta ahora la última proposición de arreglo de un viejo conflicto. En este trabajo se pretenden explicar las causas que dan origen al Plan Baker II como una propuesta de solución de compromiso entre Marruecos (en mejor posición política que jurídica) y el Frente Polisario (en mejor posición jurídica que política) tras el fracaso de las soluciones unilaterales marroquíes y la ruptura de los anteriores compromisos contraídos por Marruecos en el proceso del Plan de Paz. El aparente desequilibrio político en favor de Marruecos ha determinado una propuesta de solución que accede justamente a la mayor parte de las peticiones que hacía Marruecos e incluso a más de lo que jurídicamente podría recibir. Este Plan Baker II es un documento de gran interés jurídico que, sin embargo, suscitan algunas dudas respecto a su conformidad con el derecho internacio- 
nal vigente. Igualmente, se trata de escudriñar su valor político y qué consecuencias políticas tendría su aplicación en las políticas nacionales de los actores implicados y en la política regional magrebí. Sin embargo, las transformaciones políticas internas de Marruecos hábilmente aprovechadas por el Frente Polisario y por Argelia han puesto a Marruecos ante la difícil tesitura de rechazar un éxito internacional para no hacer frente al "coste político" de la democratización que ineludiblemente exige el Plan Baker II. Se argumentará que el rechazo de Marruecos a la solución del conflicto acorde con el derecho internacional puede tener graves consecuencias para la estabilidad de la región y constituir un peligroso precedente en la escena internacional.

\section{UN LARGO CONFLICTO JURÍDICO, YA SOLUCIONADO}

1. El conflicto del Sahara Occidental se plantea inicialmente en términos políticos, para luego hacerlo de forma jurídica, y más tarde otra vez del modo más crudamente político hasta que a partir de 1990 se debate entre ambas dimensiones.

La raíz política de este asunto se halla en la ideología nacionalista del "Gran Marruecos". En su estancia en El Cairo (1953-1956), Allal El Fassi, presidente del partido nacionalista marroquí Istiqlal elaboró sus teorías sobre el "Gran Marruecos" que sería una reconstrucción sui generis del territorio del antiguo imperio almorávide, comprendiendo todas las posesiones españolas del Norte de África (Ifni, la región de Villa Bens, todo el Sahara español, Ceuta, Melilla y los islotes), toda Mauritania, y buena parte de Argelia y de Malí, llegando hasta el río Senegal. Estas teorías nacionalistas de endeble base histórica (como puso de manifiesto el dictamen del TIJ de 1975) sin embargo, encontrarían cada vez un mayor eco político en Marruecos. ${ }^{1}$ La primera ocasión en que Marruecos va a adoptar oficialmente esa ideología será, como ha dicho Villar, el 14 de octubre de 1957, en los debates de la IV Comisión (Descolonización) de la Asamblea General de la ONU. Muy poco después, el 10 de noviembre de ese año se creará en el Ministerio del Interior de Marruecos una Dirección General de Asuntos Saharianos y Fronterizos al 
frente de la cual estará Fassi. ${ }^{2}$ Tras la muerte del rey Mohamed V, el nuevo rey Hassán II asumió la ideología del "Gran Marruecos" en un discurso de 20 de agosto de $1961^{3}$ para poco después, el 12 de octubre (día de la hispanidad) del mismo año, formular reservas sobre los territorios españoles en el Magreb. ${ }^{4}$

La situación adquiere un nuevo cariz cuando el representante español en la ONU, Piniés, acepta, el 7 de diciembre de 1963, la aplicación del principio de autodeterminación en el Sahara. ${ }^{5}$ En esta fase (años sesenta) varias resoluciones de Naciones Unidas trataron sobre el Ifni y el Sahara. Marruecos intentaba que ambos territorios se analizaran conjuntamente. Sin embargo, desde 1966 la ONU les otorgó distinto régimen jurídico: mientras el Ifni era considerado como una colonia que afectaba a la integridad territorial de Marruecos y cuya descolonización exigía la retrocesión a Marruecos, el Sahara era considerado como un problema colonial que no afectaba a la integridad territorial de ningún otro Estado y cuya descolonización exigía un referéndum de autodeterminación. ${ }^{6}$ Desde la resolución 2229 (XXI), de 20 de diciembre de 1966, la Asamblea General de Naciones Unidas viene proclamando sin interrupción que el Sahara Occidental es un territorio que debe ser descolonizado por medio de un referéndum de autodeterminación por cuanto el mismo no forma parte de la "integridad territorial" marroquí.

El rechazo en Naciones Unidas a la pretensión marroquí de considerar al Sahara como parte de su "integridad territorial" llevó a que la controversia planteada por Marruecos ya desde 1961 quedara "latente de 1966 a 1974, periodo en el que Marruecos, sin abandonar su posición jurídica, (aceptó) la aplicación del principio de autodeterminación", ${ }^{7}$ precisamente en referencia a Mauritania, territorio que reivindicaba con los mismos argumentos con los que reivindica ahora el Sahara Occidental.

2 Villar, Francisco, El proceso de autodeterminación del Sahara, Valencia, Fernando Torres, 1982 , pp. 49 y 50.

3 Ibidem, p. 80.

4 Cfr. Western Sahara, Advisory Opinion, ICJ Reports 1975, parágrafos 34 y 35.

5 Villar, op. cit., nota 2, p. 126.

6 Resoluciones 2072 (XX), de 16 de diciembre de 1965; 2229 (XXI), de 20 de diciembre de 1966; 2354 (XXII), de 19 de diciembre de 1967; Resolución 2428 (XXIII), de 18 de diciembre de 1968. Resoluciones 2229 (XXI), de 20 de diciembre; 2354 (XXII), de 19 de diciembre de 1967; 2591 (XXIV), de 15 de diciembre de 1969; 2711 (XXV), de 14 de diciembre de 1970; 2983 (XXVII), de 14 de diciembre de 1972; 3162 (XXVIII), de 14 de diciembre de 1973. Estas dos últimas hablan de autodeterminación e independencia del Sahara.

7 ICJ Reports 1975, parágrafo 36. 
Finalmente, España anunció el 20 de agosto de 1974 (varios años después de que la ONU invitara a España a hacerlo), que pensaba realizar el referéndum "dentro de los primeros seis meses de 1975", mediante una carta que el representante español en la ONU, Piniés, entregó al SG Kurt Waldheim. El conflicto del Sahara Occidental pudo haberse solucionado ya en 1975 si se hubiera celebrado el referéndum de autodeterminación que, exigido por Naciones Unidas, España se disponía a llevar a cabo en la que era, entonces, su colonia. A tal efecto, en 1974 la potencia colonizadora elaboró un censo que, aún hoy, constituye la base fundamental para la solución del problema.

A partir de ese momento, Marruecos intentó por todos los medios evitar el referéndum sabiéndose seguro perdedor. En su conferencia de prensa del 17 de septiembre de 1974, Hassán, tras una exposición histórica sobre el Sahara, plagada de tergiversaciones, lanza su sorprendente propuesta: acudir al TIJ de La Haya. Según declaró el 25 de noviembre de 1974 en la ONU el ministro marroquí Slaui, las resoluciones de ese organismo habían sido desvirtuadas por España para conseguir la creación "artificial" en "su" territorio de un nuevo Estado, cuya independencia nominal no haría sino encubrir la perpetuación del régimen colonial, con lo cual se había llegado a una "situación nueva" que imponía la suspensión del referéndum pedido por la ONU y, en consecuencia, la revisión de las directrices y criterios que llevaban consigo las resoluciones de la Asamblea General de Naciones Unidas. ${ }^{8}$

El intento de Marruecos era modificar la doctrina de la ONU. Pero para ello se requería tiempo y el referéndum ya estaba convocado. Para paralizar el referéndum se ideó acudir al TIJ pero, dado que por la vía contenciosa no era posible por la negativa de España, se pretendió llegar al tribunal por la vía consultiva a través de la ONU. Para esto se necesitaban apoyos. Marruecos consiguió hacerse del apoyo de Mauritania con el anzuelo de reconocer a ésta "derechos" sobre el Sahara, esto es, reconociendo un posible reparto. La aceptación por Mauritania de la iniciativa de Marruecos fue un hecho tristemente decisivo en la historia de la descolonización del Sahara. Por último, la torpeza de Argelia aceptando el recurso al TIJ supuso dejar sola a España y, en consecuencia, abrir la puerta a la paralización del referéndum. ${ }^{9}$ Con estos apoyos se consiguió 
aprobar la Resolución 3292 (XXIX), de 13 de diciembre de $1974,{ }^{10}$ que solicitaba el envío de una misión de la ONU al Sahara para que elaborara un informe, pedía un dictamen al TIJ y solicitaba a España que suspendiera el referéndum hasta la emisión de tales documentos, a lo que España accedió.

2. El subsiguiente dictamen del Tribunal Internacional de Justicia ${ }^{11}$ fue contundente y sentó varios principios esenciales para la futura resolución del conflicto.

En primer lugar, el tribunal declaró que nunca habían existido vínculos de "soberanía territorial" entre Marruecos y el Sahara Occidental ya que no se declaró probado que Marruecos "haya ejercido una actividad estatal efectiva y exclusiva en el Sahara Occidental" y que lo más que había ocurrido eran ciertos vínculos de vasallaje entre "ciertas, pero sólo ciertas" poblaciones nómadas del territorio y el sultán marroquí. ${ }^{12} \mathrm{De}$ esta suerte, "las conclusiones del tribunal acerca de la naturaleza de los vínculos jurídicos entre el territorio (del Sahara Occidental) y respectivamente el Reino de Marruecos y el conjunto mauritano difieren sensiblemente de las opiniones emitidas a este respecto por Marruecos y Mauritania. En opinión del tribunal, estos vínculos no implicaban ni soberanía territorial, ni cosoberanía, ni inclusión territorial en una entidad jurídica"13 (subrayados míos).

En segundo lugar, el tribunal subrayaba que el dictamen, requerido para ayudar a la Asamblea General de Naciones Unidas a pronunciarse "sobre las tesis de Marruecos y Mauritania según las cuales uno y otra habrían tenido con el Sahara Occidental vínculos jurídicos que pondrían en juego la integridad territorial de sus países", no afectaba ni modificaba "el derecho de las poblaciones del Sahara Occidental a la autodeterminación". ${ }^{14}$ El contenido del dictamen no deja absolutamente lugar a ninguna duda: el proceso de descolonización del Sahara Occidental está regido por el reconocimiento del derecho a la autodeterminación del pueblo saharaui ${ }^{15}$ pues la descolonización del territorio no afecta a la "integridad territorial” de Marruecos. Por las propias características del

\footnotetext{
10 Resolución apoyada por todos los países árabes.

11 Western Sahara, Advisory Opinion, ICJ Reports 1975, p. 12.

12 Ibidem, parágrafo 107.

13 Ibidem, parágrafo 158.

14 Ibidem, parágrafo 161.

15 Ibidem, parágrafos 70 y 161.
} 
caso, aunque se trate de una opinión consultiva, el pronunciamiento del Tribunal Internacional de Justicia debe entenderse como res judicata: el derecho a la autodeterminación del pueblo saharaui no puede ser ignorado ni negado ni vulnerado de ningún modo, por ningún órgano de Naciones Unidas. Y así, el Consejo de Seguridad en numerosas resoluciones ha reconocido el derecho a la autodeterminación del pueblo saharaui. ${ }^{16}$

En tercer lugar, el Tribunal Internacional de Justicia, por su parte, también ha expresado con claridad que este derecho a la autodeterminación corresponde a las "poblaciones" del Sahara Occidental. ${ }^{17}$ En consecuencia, no corresponde tal derecho a los "dirigentes", "gobernantes" o "líderes" del Sahara Occidental, sino propiamente a sus poblaciones, esto es, al conjunto de sus habitantes originarios.

En cuarto lugar, el Tribunal Internacional de Justicia interpretando las normas generales sobre la autodeterminación, considera las mismas como expresivas de la "necesidad fundamental de tomar en cuenta los deseos/votos (wishes/voeux) de la población afectada", aclarando que la "validez del principio de autodeterminación, definido como la necesidad de respetar la voluntad libremente expresada de los pueblos, no está afectada por el hecho de que en ciertos casos la Asamblea General no haya creído su deber exigir la consulta a los habitantes de tal o cual territorio". Para el tribunal, "estas excepciones se explican bien por la consideración de que una cierta población no constituía un "pueblo" habilitado para ejercer la autodeterminación, bien por la convicción de que una consulta sería totalmente innecesaria a la vista de circunstancias especiales". ${ }^{18}$

En conclusión, según el Tribunal Internacional de Justicia, el Sahara Occidental no forma parte de la "integridad territorial" de Marruecos y es una colonia que debe descolonizarse mediante la realización del "referéndum de autodeterminación" entre las "poblaciones" originarias del territorio.

16 S/RES/621 (1988); S/RES/658 (1990), que aprueba el Plan de Paz; S/RES/690 (1991); S/RES/725 (1991); S/RES/809 (1993); S/RES/907 (1994); S/RES/973 (1995); S/RES/995 (1995); S/RES/1002 (1995); S/RES/1017 (1995); S/RES/1033 (1995); S/RES/1042 (1996); S/RES/1056 (1996); S/RES/1084 (1996); S/RES/1108 (1997); S/RES/1131 (1997); S/RES/1133 (1997); S/RES/1163 (1998); S/RES/1185 (1998); S/RES/1198 (1998); S/RES/1204 (1998); S/RES/1292 (2000); S/RES/1301 (2000); S/RES/1309 (2000); S/RES/1324 (2000); S7RES/1342 (2001); S/RES/1349 (2001); S/RES/1359 (2001); S/RES/1429 (2002); S/RES/1495 (2003).

17 ICJ Reports 1975, parágrafos 161 y 162.

18 Ibidem, parágrafos 58 y 59. 


\section{LOS INTENTOS DE DESVIRTUAR \\ EL DERECHO INTERNACIONAL. TÍTULOS VICIADOS, POLÍTICA \\ DE HECHOS CONSUMADOS Y GUERRA}

Tras el demoledor dictamen del Tribunal de La Haya, Marruecos intentó apropiarse del Sahara Occidental por dos vías: una, la de intentar conseguir títulos jurídicos que anulasen el dictamen, tarea condenada al fracaso; la otra, simplemente, la de los hechos consumados con el auxilio de la fuerza. Ambas tácticas se utilizaron simultáneamente y tuvieron un efecto en gran medida contraproducente para Marruecos, pues los títulos jurídicos esgrimidos no consiguieron legitimar el uso de la fuerza y éste dio una relevancia política al Frente Polisario mayor de la que tenía al inicio del conflicto.

1. La primera táctica marroquí después de la derrota de La Haya fue la invasión del territorio para argüir una política de hechos consumados. La invasión se hizo por dos lugares y modos distintos, militarmente por su frontera oriental y por medio de la "marcha verde" por su frontera occidental. El Consejo de Seguridad dictó una resolución el 6 de noviembre de $1975^{19}$ exigiendo que Marruecos "retire inmediatamente del territorio los participantes en la marcha (verde)".

2. El nuevo fracaso llevó a Marruecos a intentar ganar un título jurídico para su ocupación con el Acuerdo de Madrid de 14 de noviembre de $1975 .{ }^{20}$ Sin embargo, este título, ya débil en su origen, ${ }^{21}$ tiene tres características importantes: primero, no transfiere la "soberanía" sobre el territorio, sino sólo la "administración"; segundo, esa transferencia se hace, no a Marruecos, sino a una entidad tripartita (España-Marruecos-Mauritania); y, tercero, esa transferencia opera sólo por un tiempo limitado (hasta el 26 de febrero de 1976), pasado el cual el título caduca, si es que llegó a tener validez jurídico-internacional, convirtiéndose la presencia

19 S/RES/380 (1975).

20 El texto oficial de dichos acuerdos fue difundido en una rueda de prensa en diciembre de 1975, pero nunca fue llevado a las cortes ni publicado en el Boletín Oficial del Estado. Inicialmente publicaron el texto, con diversas variantes, diversos autores, entre otros: Villar (op. cit., nota 2, pp. 346 y ss.) y Diego Aguirre. Sin embargo, el texto auténtico (en español) de este tratado, tal y como se publicó en las United Nations Treaty Series (1975, p. 258) es ligeramente distinto al reproducido por estos autores. Puede consultarse una reproducción fiel del texto auténtico en: http://www.arso.org/ac3madrid.htm.

21 Véase el conjunto de los argumentos jurídicos en favor de la nulidad de este acuerdo que se han ofrecido en mi libro El Sahara Occidental y España. Historia, política y derecho. Análisis crítico de la política exterior española, Madrid, Dykinson, 1995, pp. 119-122. 
marroquí en puramente fáctica. ${ }^{22}$ Pero no sólo eso, es que además la práctica de Naciones Unidas lo ha desautorizado. En primer lugar, sigue considerando que el problema del Sahara Occidental es un asunto de descolonización y, en efecto, el territorio se halla inscrito en la lista de territorios no autónomos y su situación es periódicamente discutida en el Comité de Descolonización. En segundo lugar, en conexión con lo anterior, y en virtud del artículo 73 e) de la Carta de Naciones Unidas, la potencia administradora de un territorio colonial debe transmitir información a Naciones Unidas acerca de los territorios de ese carácter: ${ }^{23}$ pues bien, a pesar de que en los acuerdos de Madrid se transmite la administración del territorio a un conjunto tripartito compuesto por España-Marruecos-Mauritania, los informes del secretario general de Naciones Unidas (al menos entre 1976 y 1988) aluden a la actitud española de abandonar la administración, pero nunca se refieren a Marruecos y Mauritania (ésta sólo hasta 1979) como administradoras del Sahara Occidental, sin que ello signifique en ningún caso reconocimiento de soberanía sobre tal territorio, pues el mismo se considera como descolonizable. ${ }^{24}$ En tercer lu-

22 He ofrecido este último argumento, no antes formulado, en mi artículo "El conflicto del Sahara Occidental: la difícil lucha por el derecho", La Ley, núm. 5390 (5-X-2001), pp. 1-5; y en Nación Árabe, núm. 45, vol. 15, 2001, pp. 87-103.

23 El artículo 73 e) de la carta afirma que "Los Miembros de las Naciones Unidas que tengan o asuman la responsabilidad de administrar territorios cuyos pueblos no hayan alcanzado todavía la plenitud del gobierno propio... se obligan: e) a transmitir regularmente al secretario general, a título informativo y dentro de los límites que la seguridad y consideraciones de orden constitucional requieran, la información estadística y de cualquier otra naturaleza técnica que verse sobre las condiciones económicas, sociales y educativas de los territorios por los cuales son respectivamente responsables".

24 El Yearbook of United Nations suele incluir que, con ligeras variantes, establece que "el secretario general no ha recibido información relativa al Sahara Occidental. El 26 de febrero de 1976, el representante de España había informado al secretario general que el gobierno español, a partir de esa fecha, definitivamente terminó su presencia en el territorio del Sahara y estimó necesario hacer constar que España se considera a sí misma exenta de toda responsabilidad de tipo internacional en conexión con la administración del territorio, a la vista del cese en su participación en la administración temporal establecida en el territorio" (se refiere a la administración temporal tripartita prevista en los acuerdos de Madrid). Esta cláusula, que se repite entre 1976 y 1988, es muy significativa. En primer lugar, da a entender que, según el secretario general, España debe informar sobre el Sahara, aunque excusa la falta de información aduciendo la carta del representante español. Si España debe informar es porque se la considera potencia administradora de iure. En segundo lugar, precisamente por lo anterior, el secretario general no menciona a Marruecos y a Mauritania ni tampoco los Acuerdos de Madrid, lo cual parece que implica, alternativa o acumulativamente, de un lado, el no reconocimiento por parte de Naciones Unidas de estos acuerdos y de la transferencia de la administración allí prevista, de otro lado, que esa transferencia de administración sólo se produjo hasta el 26 de febrero de 1976. Las posteriores actuaciones de la ONU contando con Marruecos para resolver la cuestión se explican por la vigencia del principio de efectividad. 
gar, diversas resoluciones de Naciones Unidas hablan de la "persistente ocupación" del Sahara Occidental por Marruecos, lo que equivale a reconocer que esa presencia no tiene títulos jurídicos, sino que sólo se apoya en los hechos consumados. ${ }^{25}$ En cuarto lugar, el dictamen de 29 de enero de 2002 del secretario general Adjunto de Asuntos Jurídicos de la ONU y asesor jurídico de la misma, Hans Corell ${ }^{26}$ dice textualmente que "El Acuerdo de Madrid no transfirió la soberanía sobre el territorio ni confirió a ninguno de los signatarios la condición de potencia administradora, condición que España, por sí sola, no podía haber transferido unilateralmente" (punto núm. 6 del dictamen). Por último, todos los planes aprobados o avalados por Naciones Unidas (tanto el Plan de Paz de 1990 y su complemento de los acuerdos de Houston, como el Plan Baker II de 2003) e incluso los proyectados (Plan Baker I) lo ignoran totalmente.

3. Desde un punto de vista jurídico, el 27 de febrero aparece un nuevo elemento, pues aprovechando el vacío legal se funda la República Árabe Saharaui Democrática (RASD) que ha llegado a ser reconocida por más de setenta países (varios de los cuales han congelado o retirado su reconocimiento después) y que fue admitida como Estado miembro de la Organización para la Unidad Africana y es uno de los Estados fundadores de la Unión Africana. El nacimiento de la RASD como Estado Saharaui que reclama como propio todo el territorio del Sahara Occidental comprendido en las fronteras internacionalmente reconocidas tiene varias consecuencias. En primer lugar, que la RASD puede alegar su derecho de legítima defensa frente a Marruecos que ha invadido su territorio. En tanto que la RASD siga controlando parte del territorio del Sahara Occidental, como ha sucedido ininterrumpidamente desde 1976 hasta hoy (actualmente controla el territorio que se encuentra al este del muro) cualquier acción militar marroquí ocupando ese territorio legitima la respuesta militar saharaui. En segundo lugar, la existencia de la RASD puede suponer que la solución del conflicto, el referéndum, no tiene como objetivo que el pueblo saharaui se pueda convertir en "un Estado independiente y soberano", pues éste ya existe, sino que sería un instrumento constituyente para que la población originaria saharaui decida si el Esta-

25 Resoluciones de la Asamblea General núm. 34/37, de 21 de noviembre de 1979 (preámbulo y puntos núms. 5 y 6); y 35/19, de 11 de noviembre de 1980 (preámbulo y puntos núms. 3 y 9).

$26 \mathrm{~S} / 2002 / 161$. 
do, ya existente, de la RASD se quiere integrar en Marruecos o si quiere seguir independiente recuperando su territorio ocupado por Marruecos. ${ }^{27}$

4. Meses después de que el acuerdo de Madrid caducara (el 27-II-1976) y de que se fundara la RASD, Marruecos buscó una nueva legitimación para su ocupación firmando con Mauritania un tratado internacional de fronteras que pretende consagrar el reparto del territorio. El tratado de 14 de abril de 1976 se llama, oficialmente, Convenio relativo al Trazado de la Frontera Estatal establecido entre la República Islámica de Mauritania y el Reino de Marruecos" y entró en vigor entre las partes el 10 de noviembre de $1976 .{ }^{28}$ Este tratado procedió a una partición del Sahara, correspondiendo a Mauritania la región sur (Río de Oro o, más exactamente, Tiris el Garbia) y a Marruecos todo el territorio saharaui al norte de la línea de demarcación pactada. Según el artículo I del tratado:

Las Altas Partes Contratantes convienen de común acuerdo que la frontera estatal establecida entre la República islámica de Mauritania y el Reino de Marruecos se halla definida por la línea recta que parte del punto de intersección de la costa atlántica con el paralelo $24^{\circ}$ norte y se dirige hacia el punto de intersección de esta línea recta con la actual frontera de la República islámica de Mauritania constituyendo el límite sureste de la frontera de Marruecos.

Este tratado, sin embargo, no sólo no otorgó a Marruecos el ansiado título jurídico para apropiarse del Sahara Occidental (o, al menos, de la mayor parte del mismo), sino que constituye un acto que desautoriza las posiciones adoptadas por Marruecos en momentos posteriores.

Por un lado, la ONU ha negado validez a la anexión del territorio operada por este tratado en varios momentos. En primer lugar, la Asamblea General de la ONU, después de aprobado este tratado calificó lo actuado por Marruecos, en dos ocasiones, como "ocupación” que es "deplorada". ${ }^{29}$ En segundo lugar, todos las resoluciones del Consejo de

27 He argumentado esta tesis en mi artículo "Recientes desarrollos del conflicto del Sahara Occidental: autodeterminación y estatalidad", Anuario Mexicano de Derecho Internacional, México, UNAM, Instituto de Investigaciones Jurídicas, vol. I, 2001, pp. 343 y ss. (p. 360).

28 El texto del tratado, cuya redacción auténtica está hecha en francés, se encuentra en United Nations Treaty Series, 1977, pp. 118 y 119.

29 Resoluciones de la Asamblea General 34/37, de 21 de noviembre de 1979, y 35/39, de 11 de noviembre de 1980 . 
Seguridad (especialmente las que aprueban el Plan de Paz de 1990, los acuerdos de Houston de 1997 y la que el Plan Baker II de 2003) se refieren a la descolonización de todo el territorio del Sahara Occidental, lo que es tanto como decir que no se reconoce ni el reparto ni la anexión del territorio operada en el tratado marroco-mauritano de 1976. En tercer lugar, el ya mencionado dictamen del asesor jurídico de la ONU, Hans Corell, de 29 de enero de $2002,{ }^{30}$ ni siquiera menciona este tratado al analizar la evolución jurídica del asunto.

Por otro lado, además de no dar a Marruecos el deseado título jurídico, el tratado marroco-mauritano de 1976 se ha vuelto contra las posiciones marroquíes defendidas con posterioridad. Así, en primer lugar, si se admite que el tratado de reparto de 1976 fue válido ello significaría que la ocupación por Marruecos de la parte sur del Sahara que Mauritania abandonó en 1979 sería un puro "acto de fuerza" violatorio de la legalidad internacional, pues Mauritania no firmó con Marruecos la entrega de ese territorio en 1979. En segundo lugar, Marruecos pierde credibilidad al oponerse a la hipótesis de la partición como fórmula de solución del conflicto, cuando ese mismo país la promovió en 1976. Además, en tercer lugar, en tanto que Marruecos firmó en 1976 un acuerdo sobre el "trazado de la frontera estatal" con Mauritania, fijando su propia frontera sur en una línea que parte de un punto que está al norte de Villa Cisneros, no puede argumentar que esta zona del Sahara forma parte de su "integridad territorial" pues, que me conste, Marruecos no ha denunciado este tratado.

5. El título jurídico indiscutible que hace valer el Frente Polisario, a saber, el derecho a la autodeterminación del Sahara Occidental, sin embargo, no ha podido ejercitarse por la ocupación militar de Marruecos de gran parte del territorio. La guerra del Sahara comenzada a finales de 1975 y continuada hasta septiembre de 1991, si bien no permitió a Marruecos controlar todo el territorio, no ha podido desalojar del Sahara ocupado a la monarquía alauí. Esta guerra comenzó apenas dos años y después de que fuera fundado el Frente Popular para la liberación de Saguia El Hamra y Río de Oro, cuando este movimiento era aún muy débil. Sin embargo, la ocupación del territorio por la guerra y la subsiguiente guerra provocó que el Frente Polisario se convirtiera en actor político mucho más importante de lo que era antes. En efecto, por un lado, el 
Frente Polisario consiguió derrotar militarmente a Mauritania lo que convierte a éste en un factor importante en la determinación de la política exterior de Mauritania, el Estado que más kilómetros de frontera tiene con el Sahara Occidental. Además, en segundo lugar, el Frente Polisario dominó al ejército marroquí, el cual sólo pudo obtener el control de la mayor parte del territorio progresivamente a partir de 1980 mediante la construcción de los muros defensivos, concluidos en 1987. Tanto las derrotas infligidas al ejército marroquí antes de la construcción de los muros cuanto el desgaste producido después de erigidos éstos (mucho mayor para Marruecos que para el Frente Polisario) atribuyeron al Frente Polisario un peso político mucho mayor al que tenía al comienzo del conflicto.

\section{EL BLOQUEO DE LAS SOLUCIONES JURÍDICAS Y POLÍTICAS. EL INTENTO DE COMPROMISO ENTRE LO JURÍDICO Y LO POLÍTICO. EL PLAN DE PAZ Y LOS ACUERDOS DE HOUSTON}

La terminación de los muros en 1987 y la transformación del conflicto en una guerra de desgaste condujo a un escenario que hacía posible la búsqueda de un compromiso. En efecto, una parte, el Frente Polisario, era portadora de un título jurídico indiscutible y un arma de presión política que era la vuelta a la guerra, y la otra, Marruecos, aun careciendo de títulos jurídicos válidos, tenía una posición política dominante en tanto que había conseguido aislar a la mayor parte del territorio de los ataques armados saharauis (que, después de la construcción del muro, perdieron profundidad). En estas condiciones la negociación para resolver el conflicto se planteó en términos en los que una parte (Marruecos) cedía parte de su predominio político (entrada de la Minurso en el territorio y admisión de la posibilidad de pérdida del territorio ocupado si el referéndum decidía la independencia) a cambio de que la otra (el Frente Polisario) flexibilizara las exigencias derivadas de su título jurídico (revisión del censo español de 1974 y admisión de la posibilidad de que el voto no fuese simplemente independencia o no, sino que la opción fuese independencia o integración en Marruecos, excluyendo otras posibilidades como integración en España o Mauritania), amén de ceder parte de sus cartas políticas (aceptación del alto el fuego). 
Esta negociación desembocó en el Plan de Paz de la OUA, asumido por la ONU en 1991. El Plan de Paz es un conjunto de textos de 1990 (el cuerpo principal del plan), 1997 (los acuerdos de Houston) y 1999 (las disposiciones pactadas para regular las apelaciones frente al censo y otras cuestiones).

El cuerpo principal fue aprobado en 1990 y $1991 .{ }^{31}$ Las resoluciones del Consejo de Seguridad que aprueban estos textos reclaman a las partes que "cooperen plenamente" en la puesta en práctica del Plan de Paz que ambas partes aceptaron. Sin embargo, el Plan de Paz fue cuestionado pronto por Marruecos (mayormente) que intentó mejorar su posición jurídica (intentando incluir en el censo de votantes al mayor número posible de marroquíes) al tiempo que intentaba mermar la posición política saharaui presionando para que algunos Estados congelaran o retiraran su reconocimiento de la RASD.

Las tensiones parecieron resolverse con un segundo texto, que completa el Plan de Paz de 1990-1991, los Acuerdos de Houston de 1997, aprobados por las partes y consagrados por el Consejo de Seguridad que pide a las partes "proseguir su cooperación constructiva con la Organización de las Naciones Unidas aplicando íntegramente" el Plan de Paz y los Acuerdos de Houston. ${ }^{32}$

El proceso de paz continuó conociendo obstáculos, fundamentalmente en tres cuestiones: el censo, el estatuto de las fuerzas militares en presencia y el de los refugiados. Sin embargo, nuevas negociaciones condujeron al tercer conjunto de textos que forma el corpus del Plan de Paz y que resuelven los litigios correspondientes al censo. Este tercer grupo de textos está constituido por un protocolo sobre la identificación de las tribus cuestionadas, directivas operacionales para proceder a la identifica-

31 Segunda parte del informe del SG (S/21360), de 18 de junio de 1990, que fue aprobado por la resolución del Consejo de Seguridad 658 (1990), que pide a las partes que "colaboren plenamente" con el secretario general de la ONU "en sus esfuerzos para lograr la pronta solución de la cuestión"; e Informe del SG (S/22464), de 19 de abril de 1991, aprobado por resolución del Consejo de Seguridad 690 (1991), que "pide a las dos partes que cooperen plenamente con el secretario general con miras a la aplicación del plan". La resolución del Consejo de Seguridad 725 (1991) vuelve a pedir a las partes que "cooperen plenamente con el secretario general para poner en práctica el plan que ellas mismas aceptaron".

32 Anexo I del informe del SG (S/1997/742), de 24 de septiembre de 1997, aprobado por resolución del Consejo de Seguridad 1133 (1997). 
ción de los individuos de estas tribus, y directivas para el estudio de las apelaciones al censo. ${ }^{33}$

El proceso iniciado en el Plan de Paz continuó con éxito. En efecto, en diciembre de 1999 concluyó la confección del nuevo censo electoral y el 17 de enero de 2000 se publicó la lista provisional de votantes que admitió como saharauis con derecho a voto a 86,386 personas de entre un total de 198,469 candidatos entrevistados por las comisiones de identificación. El nuevo censo, confeccionado por la ONU, era muy similar al español de 1974, lo que, por cierto, desmintió las acusaciones de parcialidad que Marruecos formuló contra éste. El nuevo censo, en definitiva, rechazó como saharauis a decenas de miles de marroquíes que pretendían ser incluidos en el mismo, lo que significaba que el referéndum conducía inexorablemente a la independencia del territorio.

\section{LOS INTENTOS DE MARRUECOS DE APROVECHAR SU VENTAJA PARA BUSCAR UNA "SOLUCIÓN POLÍTICA" AL MARGEN DEL DERECHO, PERO AVALADA POR ÉL MISMO. EL PLAN BAKER I}

1. La perspectiva de una derrota en el referéndum llevó a Marruecos, ante la pasividad de la ONU, a bloquearlo y romper los compromisos que contrajo en el Plan de Paz y los Acuerdos de Houston, vulnerando así lo exigido por las resoluciones 658, 690, 725 y 1133 del Consejo de Seguridad que exigían a las partes "cooperar plenamente" en la "puesta en práctica" del Plan de Paz. El bloqueo se produjo, inicialmente, presentando 120,000 apelaciones (que no constituían un obstáculo "jurídico" pues las partes habían aprobado el procedimiento para tramitarlas, ni tampoco "político" pues en un máximo de dos años habrían sido resueltas) y después declarando "caduco" el proceso. El verdadero problema era la negativa "política" de Marruecos a continuar aplicando un plan que conducía a la independencia, aunque ello significara vulnerar el "derecho".

Marruecos, violando el espíritu y la letra de los textos, pretendió que todos estos recursos fueran admitidos y estimados, lo que implicaría en realidad reiniciar todo el proceso de identificación (justamente lo que el 
Consejo de Seguridad rechazó expresamente en su resolución 1238) y, además, un retraso considerable en la celebración del referéndum. La cuestión, jurídicamente, estaba clara: la inmensa mayoría de estos recursos no cumplían los requisitos para ser admitidos pactados por las dos partes en los acuerdos de Nueva York de abril de 1999, pues en los recursos no se mencionaban las "circunstancias, hechos nuevos o cualquier elemento de prueba" que no fueron conocidos por las Comisiones de Identificación en la primera instancia y que servían para justificar la decisión de admitir a trámite la apelación. ${ }^{34}$ El propio SG ha reconocido expresamente que la resolución de las apelaciones puede hacerse de forma "sumaria" o expedita. ${ }^{35}$

Sin embargo, la ONU, lejos de sancionar o censurar el flagrante incumplimiento marroquí de las resoluciones del Consejo de Seguridad que obligaban a "cooperar plenamente" en la "puesta en práctica" del Plan de Paz, hizo caso omiso a la rebelión jurídica marroquí. En efecto, en lugar de denunciar este bloqueo y de utilizar los mecanismos que establece la Carta de Naciones Unidas para obligar a Marruecos a cumplir sus compromisos, el SG dio un espectacular giro al conflicto al solicitar la suspensión sine die del Plan de Paz (y, fundamentalmente, del referéndum $)^{36}$ y abrir la puerta a la llamada "tercera vía". El informe del secretario general de 17 de febrero de 2000, realizaba a este respecto una afirmación falaz y es que si se celebrase el referéndum y "una de las partes" (eufemismo para referirse a Marruecos) no aceptase el resultado, no habría un mecanismo coercitivo previsto en el Plan de Paz, ni parecía probable que se pudiera adoptar. ${ }^{37}$ Creo que es falaz, porque si no existe un mecanismo coercitivo en el Plan de Paz es por la sencilla razón de que tal mecanismo ya está previsto en el capítulo VII de la Carta de Naciones Unidas en el que se autoriza incluso el uso de la fuerza para hacer cumplir el eventual resultado del referéndum. Partiendo de esta discutible

34 Véanse, muy especialmente, los artículos 9.1.iii, 10.b, 12.a del Protocolo "Procedimiento de recursos en el referéndum del Sahara Occidental", y los artículos 5, 21.b y 22 del Protocolo "Directivas operacionales para la realización del proceso de apelaciones", todos éstos incluidos en el Addendum al Informe del SG (S/1999/483/Add.1), de 13 de mayo de 1999.

35 En efecto, aunque en alguna ocasión el SG ha afirmado que la resolución de las apelaciones "llevaría mucho tiempo" (S/2000/131, parágrafo 35), en otras reconoce que se puede realizar este proceso "en forma sumaria" (S/2000/1029, de 25 de octubre de 2000, parágrafo 31; S/2001/148, de 20 de febrero de 2001, parágrafo 23).

36 Informe del SG, S/2000/131, de 17 de febrero de 2000.

$37 \mathrm{~S} / 2000 / 131$, parágrafo 36; y también los informes del SG S/2000/461, de 22 de mayo, parágrafo 28; y S/2000/683, de 12 de julio de 2000, parágrafo 28. 
premisa, el secretario general de Naciones Unidas dio por fracasado el Plan de Paz y lanzó la propuesta de celebrar nuevas conversaciones directas entre las partes, con la mediación de James Baker III para alcanzar otro tipo de solución. Celebradas esas reuniones (en Berlín) no hubo ningún tipo de acuerdo, pero Marruecos presentó su propuesta de una "solución política" que coincide sustancialmente con el llamado "proyecto de acuerdo marco" que presentó James Baker en 2001 y que se conoce como Plan Baker I, aunque la autoría más que de Baker parece que es de algún jurista francés al servicio de Marruecos.

El proceso y la argumentación que llevaron a formular el proyecto de "acuerdo-marco" ofrece puntos oscuros y poco convincentes. Así, en primer lugar, para justificar el abandono del Plan de Paz firmado por las partes y aprobado por el Consejo de Seguridad, el SG argumentó que dicho plan fracasó porque era un "juego de suma cero" en el que las partes o ganaban o perdían todo. ${ }^{38}$ Ahora bien, cabría preguntarse: ¿pero no eran esas las reglas de juego que habían aceptado las dos partes? ¿por qué cambiarlas entonces? Pero se podría ir más allá. Si el fracaso del Plan de Paz se debía a que dudaba en torno a dos alternativas "de suma cero" (integración o independencia) Annan y Baker tendrían que contestar a esta pregunta: la propuesta de "autonomía" del "acuerdo-marco" que se proponía para sustituir al Plan de Paz ¿acaso no suponía aceptar una de las alternativas de la "suma cero", esto es, la integración? Y, si esto es así, ¿por qué razón el Plan de Paz debía ser desechado y el "acuerdo-marco" aceptado?

En segundo lugar, y reincidiendo en algo que se dijo en sus últimos informes, ${ }^{39}$ el SG se refería a Marruecos como "potencia administradora". ${ }^{40} \mathrm{La}$ alusión distaba de ser inocente y, precisamente por ser falsa, provocaba gravísimas contradicciones. a) De entrada, los informes del SG que atribuían a Marruecos el título jurídico de "potencia administradora" entraban en una flagrante contradicción con la doctrina sentada por la Asamblea General de Naciones Unidas tal y como se expresaba en la resolución 3458 A (XXX) de 10 de diciembre de 1975 (que se refiere, después de los Acuerdos de Madrid, a España como única potencia administradora) así como con las resoluciones 34/37 (de 1979) y 35/19 (de 
1980), todas ellas de la Asamblea General, que consideran que la actuación de Marruecos es una "ocupación" que es deplorada. b) Por otra parte, si Marruecos fuese "potencia administradora" del territorio ¿por qué entonces no cumple lo que preceptúa el artículo 73 e) de la Carta de Naciones Unidas para las potencias administradoras de territorios coloniales enviando determinadas informaciones sobre la situación del mismo? Y si no cumple eso siendo "potencia administradora" ¿por qué Annan no se lo exige? c) Finalmente, pero no lo menos importante ¿cómo es posible denominar a Marruecos "potencia administradora" del "territorio" cuando Marruecos ni siquiera ocupa todo el territorio? ¿Qué ocurre con el territorio al este del muro o berma y que actualmente se halla bajo soberanía de la RASD? ¿Se pretendía también que se sometiese a Marruecos?

En tercer lugar, el SG ofrecía como argumento para abandonar el Plan de Paz que el fracaso de éste se debió a que las partes no presentaban propuestas, sino que tenía que ser la ONU quien formulara iniciativas, abriéndose entonces un proceso de discusión entre ambas ${ }^{41}$ incentivando un juego de suma cero. Ahora bien, ¿no es el proyecto de acuerdo-marco una iniciativa de la ONU? ¿Por qué milagrosa razón entonces esta iniciativa no caería en el mismo defecto que se achacaba al Plan de Paz? Porque, "aparentemente", el proyecto resultaba ser una iniciativa de la ONU. ¿O resultaba que no era una iniciativa de la ONU? Y si no lo era de la ONU, sino de Marruecos, ¿por qué se le disfrazó como iniciativa, no marroquí, sino del secretario general? Si estuviéramos ante una iniciativa apócrifa de la ONU, nos encontraríamos con algo sumamente preocupante para la credibilidad, ya maltrecha, de Naciones Unidas.

En cuarto lugar, resultaba llamativo el desprecio poco diplomático del SG a las iniciativas del Frente Polisario, las víctimas de la ocupación, que contrastaba con la deferencia mostrada hacia el ocupante. El SG afirmó que las propuestas realizadas por el Frente Polisario para salir de la situación de bloqueo del Plan de Paz no podían ser tenidas en cuenta porque requerían bien el asentimiento de Marruecos, bien una acción del Consejo de Seguridad o bien ulteriores clarificaciones. ${ }^{42}$ Pero, ¿qué ocurría con el propio proyecto de acuerdo-marco?: ¿acaso no requería precisamente el asentimiento del Frente Polisario? el mismo SG dice que 
sí; ${ }^{43}$ ¿acaso no requería de ulteriores clarificaciones? el SG dijo que era una propuesta para ser discutida;44 ¿acaso no se proponía que el cumplimiento del acuerdo-marco no quedaría asegurado por dos miembros permanentes del Consejo de Seguridad (Estados Unidos de América y Francia)? Y si todo esto era así, ¿por qué el SG despreció las propuestas del Frente Polisario sobre el Plan de Paz y, sin embargo, avaló el proyecto de acuerdo-marco?

2. Pero si el proceso que llevó hasta el proyecto de "acuerdo marco" presentaba sospechosas oscuridades, el contenido mismo del acuerdo-marco ${ }^{45}$ propuesto no dejaba de producir perplejidad. Los problemas eran, fundamentalmente, dos: situar como premisa lo que debía ser la conclusión del proceso y considerar como conclusión del proceso lo que tenía que ser la premisa.

En primer lugar, el presupuesto de todo el texto del acuerdo marco daba por demostrado lo que precisamente se trataba de demostrar, situando como "premisa" lo que no era sino eventual "conclusión". Es decir, partía de una premisa (un a priori) que daba por demostrada y aceptada (que el Sahara Occidental es territorio de soberanía marroquí), pero que no sólo no está demostrada ni aceptada (esa soberanía no está reconocida ni por Naciones Unidas ni por los demás Estados), sino que no se puede demostrar ni aceptar sino a posteriori, hasta que después de un referéndum de autodeterminación, el pueblo saharaui eventualmente decida integrarse en Marruecos. El SG pretendía que el acuerdo marco fuese aprobado por las partes a través de una negociación de sus representantes. ${ }^{46}$ Ahora bien, el contenido del mismo conllevaba una integración en Marruecos que suponía un ejercicio del derecho de autodeterminación ya que, como es sabido, en los supuestos de descolonización por autodeterminación, el pueblo colonizado tiene varias opciones: convertirse en un Estado independiente y soberano, asociarse libremente a un Estado independiente distinto, integrarse plenamente en otro Estado independiente ${ }^{47}$ o asumir "cualquier otra condición (estatuto) política". ${ }^{48}$ Por ser un ejercicio del derecho de autodeterminación, el "acuerdo marco" tenía que ser

$43 \mathrm{~S} / 2001 / 613$, parágrafos 56 y 59 .

$44 \mathrm{~S} / 2001 / 613$, parágrafo 57.

45 El texto del "acuerdo marco sobre el status del Sahara Occidental" se encuentra en el Anexo I del S/2001/613.

$46 \mathrm{~S} / 2001 / 613$, parágrafo 54.

47 Resolución AG 1541 (XV).

48 Resolución AG 2625 (XXV). 
aprobado en referéndum. La consagración de esta premisa lógicamente aberrante (que se deduce, necesariamente, de dos puntos del acuerdo marco) era fuente de insalvables contradicciones, como no podía ser de otro modo.

De un lado, se establecía que el Reino de Marruecos tendría "competencia exclusiva" en la "preservación de la integridad territorial contra intentos secesionistas que provengan del interior o del exterior del territorio". ${ }^{49}$ Ahora bien, el Sahara Occidental sólo puede formar parte de la "integridad territorial" de Marruecos si el mismo no es un territorio colonial, sino territorio de soberanía, pues lo que caracteriza una "colonia" es, precisamente, que no forma parte de la "integridad territorial" de un Estado, ya que cuando un supuesto colonial afecta a la integridad territorial de un Estado no puede entrar en juego el principio de autodeterminación. Sin embargo, el derecho de autodeterminación del Sahara Occidental ha sido afirmado por innumerables resoluciones de la Asamblea General y el Consejo de Seguridad de Naciones Unidas y por el dictamen del Tribunal Internacional de Justicia. El acuerdo marco, por tanto, contradecía todo el derecho internacional vigente contemporáneo.

De otro, se afirmaba que "todas las leyes aprobadas por la Asamblea y todas las decisiones de los jueces... deben respetar y conformarse con la Constitución del Reino de Marruecos". ${ }^{50}$ Ahora bien, sólo era posible exigir la supremacía de la Constitución sobre el derecho del Sahara Occidental si se considerase que este territorio es de soberanía marroquí, pues la Constitución es la expresión jurídica de la soberanía. Sin embargo, lo que caracteriza a una colonia es que en la misma el ordenamiento jurídico constitucional de un Estado no tiene plena aplicación, precisamente porque no es territorio de plena soberanía (no es de soberanía "interna", aunque "externamente" esté dominado por ese Estado).

Finalmente, cabía preguntarse ¿cómo era posible compatibilizar, por una parte, la afirmación de los últimos informes del SG de que Marruecos era la "potencia administradora" del territorio ${ }^{51}$ (lo que necesariamente implica su consideración como una colonia) y, por otra, la premisa del acuerdo marco de que el territorio formaba parte de la "integridad territorial” marroquí y era, en consecuencia, territorio de soberanía?

49 “Acuerdo marco...”, núm. 2.

50 “Acuerdo marco...", núm. 4. La Constitución de Marruecos es de 13 de septiembre de 1996.

$51 \mathrm{~S} / 2000 / 1029$, parágrafo $30 ; \mathrm{S} / 2001 / 148$, parágrafos 2 y 22; S/2001/398, parágrafo 19; S/2001/613, parágrafos 2 y 42 . 
Pero, como se ha dicho, el acuerdo-marco presentaba una segunda dificultad que era situar como conclusión del proceso lo que no podía ser sino su premisa. En efecto, el resultado final del proceso descolonizador por autodeterminación puede ser muy diverso (integración, independencia, asociación), pero las normas generales sobre la descolonización previenen un procedimiento único para su realización. Así, la libre asociación debe ser resultado de una "elección libre y voluntaria de las poblaciones del territorio en cuestión, expresada según métodos democráticos"; 52 la integración debe resultar "del deseo libremente expresado de las poblaciones del territorio, plenamente conscientes del cambio de su estatuto", por medio de la elección con "métodos democráticos... imparcialmente aplicados y fundados sobre el sufragio universal de los adultos", y mediante el control de la ONU en la aplicación de esos métodos; ${ }^{53}$ la creación de un Estado independiente o la adquisición de cualquier otro estatuto político debe ser "libremente decidida por (el) pueblo". 54

En la medida en la que el proyecto de acuerdo marco establecía que "el estatuto del Sahara Occidental será sometido a un referéndum en que podrán participar los electores habilitados, en la fecha que convengan las partes en el presente acuerdo, dentro del plazo de cinco años a contar de las medidas iniciales de aplicación del presente acuerdo", 55 no se hacía sino reconocer que el nuevo estatuto del territorio no sería el resultado de los deseos libremente expresados de las poblaciones del territorio.

El acuerdo marco no sólo determinaba el estatuto del territorio vulnerando las normas generales del derecho internacional público sobre el particular, sino que contemplaba un referéndum que hacía imposible el derecho de autodeterminación. Esto se demuestra mediante el análisis del propio acuerdo marco. Por un lado, porque "estarán habilitados para

52 Resolución AG 1541 (XV), anexo, principio VII: “a) La libre asociación debe ser el resultado de la libre y voluntaria elección de los pueblos del territorio interesado expresada con conocimiento de causa y por procedimientos democráticos".

53 Resolución AG 1541 (XV), anexo, principio IX: "La integración debe producirse en las condiciones siguientes: a) El territorio que se integra debe haber alcanzado un estado avanzado de autonomía y poseer instituciones políticas libres, de modo que sus pueblos estén en condiciones de decidir, en forma responsable, con conocimiento de causa y por procedimientos democráticos. b) La integración debe ser el resultado de los deseos libremente expresados de los pueblos del territorio, plenamente enterados del cambio de su estatuto, con conocimiento de causa y por procedimientos democráticos, aplicados imparcialmente y fundados en el sufragio universal de los adultos”.

54 Resolución AG 2625 (XXV).

55 "Acuerdo marco...", núm. 5. 
votar en dicho referéndum los electores que hayan residido continuamente en el Sahara Occidental durante el año anterior", ${ }^{56}$ lo cual dejaba abierta la puerta al fraude mediante el establecimiento de colonos marroquíes. Por otro, porque al disponerse que "el estatuto del Sahara Occidental será sometido a un referéndum en que podrán participar los electores habilitados, en la fecha que convengan las partes en el presente acuerdo, dentro del plazo de cinco años a contar de las medidas iniciales de aplicación del presente acuerdo", ${ }^{57}$ se planteaban serias dudas acerca de si la opción independentista podía siquiera plantearse. Con el acuerdo marco y la Constitución sólo podrían defenderse en ese eventual referéndum dos opciones: la del mantenimiento de la autonomía dentro de la soberanía marroquí o la de "no mantenimiento de la autonomía". Esta última opción parece que sólo se podría interpretar como "plena integración", ya que no parecía que pudiera defenderse la opción independentista cuando se consagraba la atribución a Marruecos de la competencia exclusiva para la "preservación de la integridad territorial contra intentos secesionistas que provengan del interior o del exterior del territorio" $58 \mathrm{y}$ cuando el territorio se somete a una Constitución que establece que el rey, "representante supremo de la nación, símbolo de su unidad, garante de la perennidad y de la continuidad del Estado... garantiza la... integridad territorial del Reino en sus fronteras auténticas". ${ }^{59}$ La afirmación que hizo el SG en su informe de que el acuerdo marco propuesto "tiene por objeto lograr una solución pronta, duradera y convenida del conflicto del Sahara Occidental de modo que no se excluya la libre determinación sino que se facilite" 60 resultaba ser rotundamente falsa. Por lo mismo, resultaba rechazable la afirmación realizada en la resolución del Consejo de Seguridad (bien que no en la parte dispositiva) que daba vía libre a la negociación del acuerdo marco (pero que no lo aprobó), de que el mismo "entrañaría una sustancial devolución de autoridad y en el que no se precluye sino que de hecho se prevé la libre determinación". ${ }^{61}$

3. En resumen, el rechazo marroquí del "derecho" (la aplicación de la legalidad internacional vigente, esto es, el principio de autodetermina-

\footnotetext{
56 Idem.

57 Idem.

58 "Acuerdo marco...", núm. 2.

59 Artículo 19 de la Constitución marroquí de 13 de septiembre de 1996.

$60 \mathrm{~S} / 2001 / 613$, parágrafo 54.

61 S/RES/1359 (2001), párrafo 8o. del preámbulo.
} 
ción exigido por el Tribunal Internacional de Justicia, la Asamblea General y el Consejo de Seguridad de la ONU) condujo a una ofensiva diplomática dirigida a sustituir el mismo por una "solución política" (es decir, un acuerdo de los respectivos dirigentes sin proceder al referéndum) que estableciera supuestamente una "amplia autonomía" en "el marco de la soberanía marroquí". Esa ofensiva contó con la complacencia del secretario general de la ONU, que en su informe de 31 de mayo de 2001 asumió la presentación de esa "solución política" (llamada por algunos "tercera vía") que se concretó en el "Proyecto de Acuerdo Marco" conocido como primer Plan Baker. Sin embargo, el intento marroquí de desvirtuar la legalidad internacional existente fracasó cuando el Consejo de Seguridad, en su resolución 1429 de 30 de julio de 2002, se negó a aprobar el Plan Baker II y rechazó un "acuerdo político" que no permitiera la "autodeterminación".

A partir de entonces, cerrado el camino de la "solución política" pretendida por Marruecos, el único camino para anular el temido Plan de Paz era "aguarlo" con una fórmula que conjugara las dos posibilidades: un "acuerdo político" que atribuyera al Sahara una autonomía bajo control marroquí como pretendía la monarquía alauita y, a la vez, hiciera posible la autodeterminación del territorio como desea el Frente Polisario. En esto consiste básicamente el Plan Baker II.

\section{LAS VÍAS DE SOLUCIÓN ABORTADAS. LA ADMINISTRACIÓN DIRECTA POR NACIONES UNIDAS Y LA PARTICIÓN}

La "propuesta de acuerdo marco" o Plan Baker I, como se ha dicho, constituía una pura y simple anexión a Marruecos de todo el territorio del Sahara Occidental. Como señuelo se ofrecía una supuesta autonomía que no lo era sino en precario, pues carecía de las mínimas garantías. Por ello no resultó en absoluto sorprendente que el mismo fuera rechazado por el Frente Polisario y por Argelia. La situación parecía así totalmente bloqueada: el Plan de Paz (aprobado por el Consejo de Seguridad) era la única solución aceptada por las partes, pero Marruecos incumplió sus compromisos; el Plan Baker I (no aprobado por el Consejo de Seguridad) no permitía llegar a ningún compromiso. Para romper el bloqueo se exploraron dos posibles soluciones: la administración directa por las Naciones Unidas y la partición. 
1. La propuesta de administración directa del territorio por las Naciones Unidas fue sugerida por Argelia en su respuesta al Plan Baker I. ${ }^{62} \mathrm{La}$ propuesta argelina era que, dado que existía una solución que había sido aceptada por ambas partes (el Plan de Paz) y aprobada por la ONU y que, dado que los obstáculos provenían de las divergencias entre éstas en su aplicación, lo más juicioso era que la propia ONU asumiera soberanamente la aplicación de su propio plan (es decir, el Plan de Paz). Argelia presentó bastantes detalles de esta propuesta. El eje fundamental es que antes del referéndum habría un breve periodo de transición en el que el territorio del Sahara Occidental estaría "bajo la autoridad y la administración exclusivas" de la ONU. De esta forma, se podría consolidar la confianza entre las dos partes, ya que la seguridad pública y la organización del referéndum no se haría ni por una parte ni por otra, sino por un tercero.

La propuesta argelina fue rechazada sin muchas explicaciones por el secretario general, pese a ser la única que, verdaderamente, consagraba una solución (al menos, transitoria) sin vencedores ni vencidos pues, si bien Marruecos debía abandonar el territorio, éste no podría tampoco ser ocupado por el Frente Polisario, por lo cual quedaban las tropas de ambos contendientes acantonadas conforme a lo previsto en el Plan de Paz.

2. La otra propuesta de solución no la formuló ninguna de las partes, sino que la sugirió oficialmente Kofi Annan y el propio James Baker en el 2002.63 Se trataba de la posibilidad de proceder a una partición del territorio. Concretamente, el SG de la ONU afirmó que:

El Consejo de Seguridad podría pedir a mi enviado personal que tratara por última vez de determinar con las partes si estarían o no dispuestas a considerar, bajo sus auspicios y mediante conversaciones directas o indirectas, una posible división del Territorio, en la inteligencia de que no se decidiría nada hasta que quedara decidido todo. Si el Consejo de Seguridad se inclinase por esta opción y en el caso de que las partes no estuvie-

62 "Observaciones del gobierno de Argelia relativas al proyecto de acuerdo marco para el Sahara Occidental", Anexo II del Informe del secretario general de 10 de enero de 2002 (S/2002/41). Véanse especialmente los parágrafos 8-12 de las "Observaciones" de Argelia.

63 Aunque Marruecos inmediatamente acusó a Argelia de "inspirar" la partición para satisfacer sus ansias "expansionistas", lo cierto es que oficiosamente la tesis ya circuló cuatro años antes. En 1998, Annan consultó oficiosamente esta posibilidad que promovió Estados Unidos de América. En aquel entonces, "fuentes oficiosas marroquíes... no ocultan una cierta satisfacción ante la misma". El Pais, 22-XII-1998, p. 12. 
sen dispuestas a llegar a un acuerdo respecto de una división del territorio para el 1o. de noviembre de 2002, o no pudieran hacerlo, se pediría también a mi enviado personal que les presentase posteriormente una propuesta de división del territorio que sería sometida también al Consejo de Seguridad. El Consejo de Seguridad sometería esta propuesta a las partes en el entendimiento de que no estaría sujeta a negociación. Esta forma de llegar a una solución política daría a cada una de las partes algo de lo que quiere, pero no todo, y seguiría el precedente, aunque no necesariamente los mismos arreglos territoriales, de la división convenida en 1976 entre Marruecos y Mauritania. ${ }^{64}$

La tesis de la partición podría haber resultado interesante en la medida en que todas las partes en conflicto quedarían satisfechas: Marruecos porque se quedaría con la zona en la que más gastos ha hecho; Francia porque su aliado podría al menos conservar parte de lo ocupado; la RASD porque vería consagrada su existencia por toda la comunidad internacional; Argelia porque conseguiría aliviar la presión geoestratégica en su frontera suroccidental; Mauritania porque, al perder su frontera con Marruecos, vería su existencia garantizada frente al imperialismo marroquí mediante la existencia de un "Estado colchón"; Estados Unidos de América conseguiría la paz en el Magreb y se eliminarían los obstáculos para la creación del gran mercado único del Magreb; y, finalmente, España porque conseguiría que concluyera con un relativo éxito la descolonización y se abriese un espacio socio-económico de cooperación con la RASD.

Ahora bien, la partición era una hipótesis no exenta de problemas. El primero, y fundamental: cuál sería el territorio que correspondiese a cada una de las partes. Aunque los medios presentaron la partición como una repetición de la operación realizada en 1976 entre Marruecos y Mauritania, la lectura del pasaje del informe del SG revela que en la propuesta onusiana el arreglo territorial no necesariamente iba a ser el mismo, y es lógico que así fuera. Una división del territorio entre Marruecos y la RASD igual que la que se hizo en 1976 resultaría inviable por muchas razones. La primera es que una tal división del territorio implicaría que la RASD perdería una buena parte del territorio que ahora controla, esto es, el que está al este del muro o berma, y que se halla al norte de la línea di-

64 La propuesta de partición se presenta como iniciativa de James Baker y del propio Kofi Annan en el informe S/2002/178, de 19 de febrero de 2002, parágrafo 50. 
visoria del reparto marroco-mauritano. La segunda es que tal división implicaría que la RASD perdería su frontera con Argelia, con lo cual dejaría de tener sentido el argumento que se ofrece de que esta partición permitiría una salida al Atlántico para Argelia a través de la RASD. En tercer lugar, esta división conllevaría que Marruecos quedaría con un territorio que es, precisamente, el de la tribu más belicosamente antimarroquí de las tribus del Sahara Occidental, los Erguibat. Por todo ello, para que la eventual partición tuviera mínimas posibilidades de poder ser considerada, se requeriría una línea divisoria entre Marruecos y la RASD muy distinta de la de 1976. En primer lugar, la línea de demarcación de 1976 tendría que ampliarse hacia el noroeste para que el territorio de la RASD en el futuro incluyera todos los actuales territorios liberados que domina en este momento la RASD. No sería admisible que territorios liberados, que ahora son de la RASD, tan simbólicos como Bir Lehlú (lugar de fundación de la RASD y capital provisional de la misma hoy día) o Tifariti (donde se ha celebrado el XI Congreso del Frente Polisario) quedaran en manos de Marruecos. Esta sería la única manera de que la RASD mantuviera frontera con Argelia. En segundo lugar, la actual frontera oriental entre Marruecos y la RASD tendría que ampliarse hacia el oeste para que el territorio de la RASD, de no poder contar con El Aaiún, sí pudiera contar al menos con Smara, capital espiritual del territorio, ubicada como El Aaiún en una zona erguibat, y que eventualmente podría convertirse en capital de la RASD. En tercer lugar, la línea de demarcación también tendría que desplazarse más al norte, abarcando la ciudad de Bojador en la costa Bojador y repartiendo la zona de Bu Craa en el interior para que ambos Estados pudieran beneficiarse por igual de los fosfatos y de las riquezas pesqueras. Además, y esto es muy importante, se conseguiría vecindad con Canarias, para lo cual la RASD tendría que poseer, como se ha dicho, Bojador.

El segundo problema de la partición sería que jurídicamente también debería ser avalada por un referéndum, pues este mecanismo es esencial para proceder a la descolonización. El tercer problema sería político por cuanto que una partición podría aumentar el sentimiento irredentista saharaui ya herido tras el desgraciado tratado de 1912 que privó al Sahara Occidental del territorio comprendido entre el paralelo 27'40 y el río Draa para atribuírselo al sultán marroquí (aunque nunca lo poseyó antes). Ahora el territorio del Sahara sufriría una nueva amputación. 
VII. EL FRACASO DEL INTENTO DE EXIMIRSE DEL DERECHO INTERNACIONAL Y LA PROPUESTA DE SOLUCIÓN DE COMPROMISO TEÓRICAMENTE FAVORABLE A MARRUECOS. EL PLAN BAKER II

1. La tosquedad jurídica del llamado Plan Baker I y la inviabilidad política del mismo (resultaba una anexión de todo el territorio apenas disimulada) condujeron a su fracaso. El fracaso se hizo tanto más evidente cuanto que el Consejo de Seguridad no lo llegó a aprobar en ningún momento. Lo máximo que consiguió Marruecos fue que la resolución 1359 del consejo ${ }^{65}$ alentara "a las partes a que examinen el proyecto de acuerdo marco y negocien cualesquiera modificaciones concretas que deseen introducir en esta propuesta", pero sin por ello cerrar la puerta a otras posibles vías, pues también se permitía que "examinen cualesquiera otras propuestas para alcanzar una solución política que puedan presentar las partes para llegar a un acuerdo mutuamente aceptable". El único logro para Marruecos fue que esta resolución no mencionara la "autodeterminación" en la parte dispositiva, aunque sí se refiriera a ella en el preámbulo. Pero el logro fue efímero. La elusión del derecho internacional a la autodeterminación del Sahara Occidental consagrado por decenas de resoluciones de la Asamblea General, por múltiples resoluciones del Consejo de Seguridad y por el propio Tribunal Internacional de Justicia podía tener consecuencias gravísimas para el derecho internacional, creando un precedente de peligrosidad extrema. Las alarmas sonaron en todos los niveles. No casualmente, después de la resolución 1359 (de junio de 2001), el asesor jurídico de Naciones Unidas, Hans Corell, emitió su demoledor dictamen (de 29 de enero de 2002) sobre los contratos petrolíferos en el Sahara Occidental reiterando la doctrina sobre la autodeterminación del derecho internacional de las Naciones Unidas. La resolución 1429 intentó evitar esta deriva peligrosísima que ponía en cuestión todo el derecho internacional de la descolonización de los últimos decenios. Esta resolución afirmaba que el Consejo de Seguridad seguía "apoyando decididamente la labor del secretario general y de su enviado personal orientada a encontrar una solución política a esta controversia", pero matizó que esto debía hacerse "teniendo en cuenta las preocupaciones manifestadas por las partes" (en este caso, el Frente Polisario y Argelia), y expresa su disposición a examinar "cualquier propuesta relativa al 
derecho de libre determinación que presenten el secretario general y el enviado personal, en consulta, según proceda, con otras entidades que tengan la experiencia pertinente". El derecho de autodeterminación, que parecía expulsado de la resolución 1359 (aparecía en el preámbulo, pero no en su parte dispositiva) volvía de nuevo como eje inexcusable para resolver el conflicto.

2. El Plan de Paz para la Autodeterminación del Pueblo del Sahara Occidental o Plan Baker II, trasluce la autoría de un constitucionalista estadounidense. Este plan fue propuesto por James Baker a las partes en la gira que efectuó por la región en enero de 2003. El texto concreto del plan tardó en trascender a la opinión pública pues Baker exigió máxima reserva. Finalmente, se hizo público al ser incluido, junto con los comentarios de las partes, en el informe del SG sobre la situación del Sahara de mayo de 2003. ${ }^{66}$ Las respuestas de las partes a la propuesta que les hizo llegar Baker resultaron un tanto desconcertantes. En primer lugar, $\mathrm{Ma}$ rruecos expresó su rechazo a este plan, desconcertante porque, como más adelante se argumenta, le era bastante favorable. ${ }^{67}$ En segundo lugar, el Frente Polisario también expresó su rechazo, ${ }^{68}$ menos desconcertante, dado que este plan representaba un cambio desfavorable para el Frente en relación con el "Plan de Paz" de 1990-1991 y los Acuerdos de Houston de 1997. Por eso mismo, resultó sumamente sorpresivo que muy poco después el Frente Polisario que en un principio había mostrado sus críticas al plan, lo aceptase justo antes del debate sobre el mismo en el Consejo de Seguridad. ${ }^{69}$ En tercer lugar, constituyó también algo inesperado la aceptación con reservas que formuló Argelia. ${ }^{70}$ Finalmente, en cuarto lugar, Mauritania expresó su apoyo al plan sin ningún tipo de re-

66 S/2003/565, de 23 de mayo de 2003. El texto del Plan Baker II se incluye como Anexo II del Informe y las respuestas de las partes como Anexo III.

67 Observaciones del Reino de Marruecos sobre la nueva propuesta del señor James Baker titulada: "Plan de paz para la libre determinación del pueblo del Sahara Occidental" [en el Anexo III del $\mathrm{S} / 2003 / 565]$.

68 Carta de fecha 8 de marzo de 2003 dirigida al secretario general, por el secretario general del Frente Polisario [en el Anexo III del S/2003/565].

69 Carta del Frente Polisario al SG de Naciones Unidas de 6 de julio de 2003.

70 Carta de fecha 26 de febrero de 2003 dirigida al secretario general por el presidente de Argelia en la que se incluye el Memorando de Argelia sobre la nueva propuesta del enviado personal del secretario general a las Naciones Unidas que lleva por título "Plan de paz para la libre determinación del pueblo del Sahara Occidental" [en el Anexo III del S/2003/565]. 
servas. ${ }^{71}$ Después de examinar todas las observaciones de las partes, el Consejo de Seguridad (en aquel mes presidido por España) apoyó el Plan Baker II por unanimidad en su resolución 1495. ${ }^{72}$

El contexto de este plan es el de una parte, la marroquí, con el dominio político marroquí sobre la mayor parte del territorio, y otra parte, la saharaui, con un título jurídico indiscutible al derecho a la autodeterminación, con una situación en los campamentos de refugiados cada vez más tensa y con un serio riesgo de reanudación de hostilidades por unidades saharauis descontroladas. El borrador de resolución presentado por Estados Unidos de América decía que el Consejo de Seguridad "aprobaba” el Plan Baker II. Esta redacción, que implicaba la imposición del plan a las partes, acogía la observación del secretario general de que nuevas negociaciones entre las partes no sólo no darían resultado sino que incluso serían contraproducentes. ${ }^{73}$ Sin embargo, la férrea oposición de Marruecos, canalizada por Francia, a la imposición del texto a las partes, llevó a la definitiva redacción que mitiga el precepto sustancialmente en el plano jurídico, aunque mantiene su fuerza política. Desde un punto de vista jurídico, el texto definitivo de la resolución dice que el consejo no "aprueba", sino que "apoya" el Plan Baker II (lo que es tanto como aprobarlo "políticamente" aunque no "jurídicamente"). En este sentido pide a las dos partes que cooperen con la ONU y entre sí con vistas a la "aceptación" y "aplicación” del plan. Por tanto, jurídicamente, el plan no está aprobado sino que es una mera propuesta cuya aprobación y aplicación sigue condicionada a la aceptación de las dos partes. Si desde un punto de vista jurídico, la resolución 1495 fue recortada sustancialmente, desde un punto de vista político, sin embargo, el consejo ha dado al mismo un aval político indiscutible al "apoyarlo enérgicamente" y considerarlo "una solución política óptima que reposa sobre el acuerdo de las partes".

3. El análisis comparativo entre el llamado Plan Baker I y el Plan Baker II ofrece seis diferencias fundamentales.

En primer lugar, el Plan Baker I sólo menciona expresamente las competencias exclusivas del Reino de Marruecos (artículo 2), guardando silencio y, por ende, dejando al arbitrio del intérprete (quien sea el intérprete, como veremos, es otra diferencia axial) la determinación de las

71 Nota verbal de fecha 17 de marzo de 2003, dirigida al secretario general por la Misión Permanente de Mauritania ante las Naciones Unidas [en el Anexo III del S/2003/565].

72 S/RES/1495 (2003), de 31 de julio de 2003.

73 S/RES/1495 (2003), parágrafos 56 y 58. 
competencias que corresponden a la Autoridad del Sahara Occidental (ASO). Sin embargo, el Plan Baker II protege mejor los intereses saharauis al determinar expresamente no sólo las competencias exclusivas de Marruecos (artículo 8.B), sino también las de la ASO (artículo 8.A).

En segundo lugar, el Plan Baker II reduce las competencias que correspondían al Reino de Marruecos en el Plan Baker I. Si éste atribuía al reino la competencia exclusiva sobre "todas las cuestiones" relativas al "uso de armas", el Plan Baker II establece una excepción al permitir que la ASO pueda tener competencia exclusiva en el uso de las armas para garantizar la "seguridad interior y el mantenimiento del orden" (artículo 8.A).

En tercer lugar, el Plan Baker II amplía los derechos fundamentales de los ciudadanos del Sahara, tanto de forma genérica (artículo 13, que establece que las normas de la ASO deberán respetar los convenios internacionales de derechos humanos, sin poder reducir el nivel de protección del derecho marroquí), cuanto de forma específica (artículo 8.B que instituye una garantía expresa de la libertad de expresión para defender la independencia). Sin embargo, en el Plan Baker I, los saharauis sólo tienen los derechos que les atribuya el ordenamiento marroquí que, como recientes casos han puesto de manifiesto, ${ }^{74}$ es sumamente restrictivo con los derechos fundamentales y, en especial, con la libertad de expresión.

En cuarto lugar, mientras el Plan Baker I establece que las leyes de la ASO deberán ser conformes con la Constitución marroquí (artículo 4), la cual limita las posibilidades de la autonomía, pues sólo reconoce una autonomía local, entre otros preceptos restrictivos, el Plan Baker II dispone que sólo tendrán que ser conformes con la Constitución marroquí las propias leyes que dicte la administración marroquí en el territorio, pues las leyes que dicte la ASO no tendrán que ser conformes con la Constitución marroquí, sino con el Plan Baker II (artículo 12), que se erige así en la auténtica Constitución del territorio en el periodo transitorio previo al referéndum de autodeterminación. Esta cláusula permite argumentar que antes del referéndum de autodeterminación no hay "integración” en Marruecos a diferencia de lo que ocurría con el Plan Baker I.

74 Casos de cierres de medios de comunicación a finales de 2001 por orden gubernativa, encarcelamiento de activistas pacíficos saharauis como Alí Salem Tamek, encarcelamiento del periodista Alí Lmrabet, etcétera. 
En quinto lugar, en caso de divergencia a la hora de aplicar el plan entre la administración marroquí y la ASO, del Plan Baker I se desprendía implícitamente que, puesto que las leyes de la ASO debían ser conformes con la Constitución marroquí (artículo 4), quien resolvía los conflictos es quien, según esa Constitución marroquí resuelve los conflictos, a saber, en gran medida el Consejo Constitucional, la mayoría absoluta de cuyos miembros es designada por el rey. Sin embargo, en el Plan Baker II, en caso de conflicto entre la administración o una ley marroquí y la administración o una ley saharaui, quien resuelve los conflictos es un tercero neutral, el secretario general de la ONU (artículo 22), lo cuál es coherente con considerar al Plan Baker II como la norma suprema o Constitución del territorio en el periodo transitorio.

Finalmente, en sexto lugar, mientras el Plan Baker I abría la posibilidad de que participaran en el referéndum de autodeterminación a todos los que residieran en el territorio desde un año antes de la celebración del mismo (artículo 5) dejando, además, sin solución el problema de los conflictos en la determinación del cuerpo de votantes, el Plan Baker II establece un censo mucho más preciso para participar en el referéndum de autodeterminación. Como se verá más adelante, en este acto participarán los que estén comprendidos en tres listas: la de votantes reconocidos como saharauis por la ONU en diciembre de 1999, la de refugiados saharauis de ACNUR y la de todos aquellos que residan en el territorio de forma continuada desde antes de 1999. Además, en caso de conflicto, sólo el SG de la ONU puede decidir quien estará admitido a participar en el referéndum.

4. La historia reciente del Sahara Occidental pone de manifiesto que la monarquía alauita ha ido persiguiendo tres objetivos: 1) Un título jurídico que legitime la ocupación del Sahara (ya sea de "soberanía" ya de "administración" como en el Acuerdo de Madrid que atribuyó el título de "co-administrador", aunque como se vio este título ha caducado); 2) Un control sobre todo el territorio (pretendido antes de la crisis de noviembre de 1975, abandonado tácticamente para involucrar a Mauritania en su favor y retomado en 1979 tras el abandono mauritano de la parte del Sahara que le correspondió en el reparto); y 3) Un censo con una composición mayoritaria de marroquíes para garantizar un resultado favorable (objetivo perseguido en todo el proceso iniciado con el Plan de Paz). A cambio de conseguir estos tres objetivos, Marruecos, ya desde la época de Hassán II, ha ofrecido como contrapartida la de otorgar al Saha- 
ra una "autonomía” que Hassán II llegó a afirmar como de tipo federal en cuanto inspirada en la de los Länder alemanes. ${ }^{75}$

Pues bien, un análisis objetivo del Plan Baker II nos ofrece un producto en el que Marruecos obtiene todo lo que puede obtener y quizás más incluso. Veámoslo.

a) En primer lugar, Marruecos obtiene un título jurídico para su ocupación, un título que Marruecos pretendía y que hasta ahora nunca ha poseído. Es significativo el silencio del Plan Baker II sobre el acuerdo de Madrid de 14 de noviembre de 1975 y sobre el tratado de delimitación de fronteras con Mauritania de 14 de abril de 1976 (en el que se pacta el reparto del Sahara). Este silencio es coherente con el dictamen del asesor jurídico de Naciones Unidas, Hans Corell, de 29 de enero de 2002 que niega a Marruecos cualquier título jurídico para su ocupación del Sahara. Esto significaba que hasta ahora todas las acciones llevadas a cabo por Marruecos en el territorio estaban amenazadas de ilegalidad internacional (por ejemplo, las concesiones de explotación petrolífera). El Plan Baker II atribuye a Marruecos un título jurídico para su ocupación, permitiéndole gestionar sus relaciones exteriores, su defensa exterior y la delimitación de sus fronteras.

Cuestión distinta es la de qué título jurídico es ese: si de "soberanía" como pretende Marruecos o de "administración". Desde el punto de vista jurídico-internacional, la atribución de soberanía sobre el territorio sólo es admisible después del referéndum de autodeterminación. Por eso, una lectura del Plan Baker II estimando, como pretende Marruecos, que establece una "autonomía en el marco de la soberanía marroquí" no parece correcta. Antes bien, el Plan Baker II debe ser interpretado de acuerdo con la legalidad internacional y una tal interpretación sólo permite inferir que lo que recibe Marruecos es un título de "administración", más concretamente, de "co-administración" conjuntamente con la ASO. En mi opinión una lectura cuidadosa del Plan Baker II conduce a esta conclusión. En efecto, si bien las leyes de la administración marroquí en el Sahara deben ser conformes con la Constitución marroquí, las leyes del Parlamento saharaui no deben someterse a la Constitución marroquí... ¡sino al Plan Baker II! que opera así como la auténtica Constitución del

75 En la primavera de 1988, en el palacio de Marraquech, el rey anunció que su proyecto de administración pública para Marruecos pasaba en un futuro más o menos próximo por el modelo descentralizador de los länder alemanes, tras estudiar también de manera concienzuda el autonómico español. 
territorio. ${ }^{76}$ Es esta una diferencia fundamental respecto al Plan Baker I que sometía las leyes saharauis a la Constitución marroquí. Por esto mismo hay dos objeciones marroquíes al plan que estimo infundadas. Por un lado, no parece una contradicción, como pretende Marruecos, el decir que el secretario general tiene competencia para interpretar el Plan de Paz, ${ }^{77}$ cuando también tienen esa competencia los tribunales supremos saharaui y marroquí. Precisamente, lo que dice el Plan Baker II es que la interpretación del secretario general del plan se impone en caso de desacuerdo. En definitiva, si la Constitución es la normal expresión de una soberanía, el Plan Baker II es la auténtica Constitución saharaui en el periodo previo al referéndum y, por tanto, la soberanía no es de Marruecos. Por otro lado, tampoco parece admisible el argumento marroquí de que el Plan Baker II no podría entrar en vigor sino cuando el mismo sea ratificado por Marruecos (y por los demás firmantes: Frente Polisario, Argelia y Mauritania) con arreglo al procedimiento previsto en su Constitución, ya que, según la monarquía alauita, este plan implica "modificaciones sustanciales del status de las provincias del sur del país". ${ }^{78}$ No me parece admisible este argumento por cuatro razones. La primera es que el Plan de Paz de 1990 y los Acuerdos de Houston, igualmente aprobados por el Consejo de Seguridad, también implicaban "modificaciones sustanciales del status de las provincias del sur del país" y Marruecos no tuvo que modificar su Constitución para aplicarlos. La segunda es que el Plan Baker II no es un "tratado internacional", sino una resolución del Consejo de Seguridad . El hecho de que su puesta en práctica se someta a la aceptación de las partes es una condición de "aplicabilidad", pero no de "validez". La tercera es que la Constitución marroquí no menciona expresamente a esas "provincias del sur", por lo que no tiene validez este argumento, inspirado en el dictamen del Tribunal Supremo canadiense de 20 de agosto de 1998 en relación con Québec, territorio que, como bien dijo el TS canadiense no es una colonia, sino uno de los Estados que conforman la Federación canadiense según la Constitución de aquel país. Finalmente, la cuarta razón es que el derecho internacional no puede estar condicionado por una cláusula de una

76 Artículo 12 del Plan Baker II.

77 Artículo 22 del Plan Baker II. Véase el parágrafo 22 de las "Observaciones del Reino de Marruecos sobre la nueva propuesta del señor James Baker titulada: 'Plan de paz para la libre determinación del pueblo del Sahara Occidental"'.

78 Parágrafo 1 de las "Observaciones del Reino de Marruecos...". 
Constitución que haya sido introducida con vulneración del derecho internacional.

b) En segundo lugar, con el Plan Baker II, Marruecos conseguiría lo que nunca ha conseguido hasta ahora, como bien recuerda Argelia en su respuesta al plan, a saber, un control sobre todo el territorio..$^{79}$ Bien fuera porque en 1975-1976 el Sahara se repartió entre Marruecos y Mauritania, o porque antes de la construcción de los muros apenas controlaba el territorio, o porque después de la construcción de éstos, sólo controla el perímetro englobado por los mismos, es lo cierto que desde 1976 hasta la fecha siempre ha habido un territorio (en la actualidad el 20 por ciento, aproximadamente) conocido como "liberado" en el que el control ha recaído exclusivamente en la RASD. El Plan Baker II ignora completamente la existencia de la RASD (lo que no puede ser sino de agrado marroquí) y priva a ésta de todo su territorio propio, atribuyendo al ejército marroquí el control de las "fronteras exteriores". Este control sobre todo el territorio plantea problemas políticos y jurídicos.

Políticamente Argelia expresa su temor de que en el Sahara las tropas marroquíes puedan encontrarse enfrente de las argelinas al desaparecer el "espacio colchón" controlado por el Frente Polisario. Para Mauritania se plantea la cuestión sobre qué sucedería si las tropas marroquíes tuvieran, por primera vez, presencia inmediata ante las fronteras mauritanas. No se olvide que Marruecos reivindicó la anexión de Mauritania con los mismos argumentos empleados para anexionarse el Sahara. Finalmente, para el Frente Polisario esta cláusula significa, nada más y nada menos, que todas sus tropas estarán rodeadas por el ejército marroquí.

Jurídicamente es cierto que las únicas fronteras exteriores reconocidas son las que delimitan el conjunto del territorio. Sin embargo, también jurídicamente la RASD es un Estado existente que es miembro de la Unión Africana y que reivindica como propio el territorio comprendido en las fronteras internacionalmente reconocidas. Ciertamente, la UA y la

79 Memorando de Argelia sobre la nueva propuesta del enviado personal del secretario general a las Naciones Unidas que lleva por título "Plan de paz para la libre determinación del pueblo del Sahara Occidental": "Argelia desea subrayar que desde el desencadenamiento del conflicto armado en el Sahara Occidental en 1975 ni ella en su propio territorio ni Marruecos en el territorio del Sahara Occidental han desplegado fuerzas armadas en la frontera internacionalmente reconocida entre Argelia y el Sahara Occidental. Las fuerzas armadas marroquíes están desplegadas en el muro de arena que se sitúa a una decena de kilómetros de la frontera internacional entre Argelia y el Sahara Occidental" (texto extraído de la parte IV. La cuestión de las tropas de las dos partes del memorando). 
ONU son organizaciones distintas y, por tanto, lo que suceda en la UA no tiene por qué condicionar lo que haga la ONU. Dado que el Plan Baker II se ofrece a la firma del Frente Polisario (único interlocutor reconocido por la ONU) y no de la RASD se plantea el problema de si lo que decida el Frente Polisario puede vincular a la RASD, pues si en la práctica hay casi total coincidencia entre ambas entidades en teoría no es así. La admisión en la ONU no es condición para la existencia de un Estado. El hecho de que exista la RASD y cuente con su territorio pudiera llegar a plantear la cuestión de qué ocurriría si el ejército marroquí fuera a tomar el control de las fronteras internacionalmente reconocidas saliendo del muro. Si la RASD no diera su aceptación al acuerdo podríamos encontrarnos ante un supuesto de invasión armada del territorio de un Estado (la RASD) por otro (Marruecos) lo que daría un título de "legítima defensa" para reiniciar la guerra.

c) En tercer lugar, y ante la perspectiva de celebrar un inexorable e inevitable referéndum de autodeterminación, Marruecos ha venido pretendiendo "inflar" el censo de votantes con la inclusión de marroquíes. Ya en 1975, cuando la ONU envió una misión visitadora al territorio, Marruecos afirmó que había fuera del territorio "de 30,000 a 40,000" saharauis que vivían en Marruecos y Mauritania como supuestos refugiados que huyeron de la represión española. ${ }^{80}$ Una vez constatada la práctica unanimidad saharaui por la independencia, Marruecos decidió incrementar la cifra de supuestos "saharauis" que debían ser incluidos. Hassán II, en carta de 15 de septiembre de 1991, dirigida al secretario general estimó los mismos en "170,000" y anunció que procedía a su "reunión" en el mismo Sahara. El Plan Baker II establece para la elección presidencial y parlamentaria en la fase previa al referéndum un cuerpo electoral del que forman parte sólo las personas consideradas como saharauis por las Comisiones de Identificación de la ONU (86,386). Sin embargo, dispone que para el referéndum de autodeterminación votarán, además de éstos, los refugiados inscritos en la lista de repatriación elaborada el 31 de octubre de 2000 por el Alto Comisionado de Naciones Unidas para los Refugiados (lista que es desconocida para Marruecos) y los "residentes" de forma continuada en el Sahara desde el 30 de diciembre de 1999 (en las

80 Parágrafo 9 del Informe del Comité Especial encargado de Examinar la Situación con respecto a la Aplicación de la Declaración sobre la Concesión de la Independencia a los Países y Pueblos Coloniales, Nueva York, Naciones Unidas, vol. III (XXX-suplemento núm. 23), 1977, pp. 12 y ss. 
últimas elecciones legislativas marroquíes figuraban como "residentes" en el territorio 151,696 personas, incluidos los aproximadamente 45,000 saharauis reconocidos como votantes por la Minurso que "residen" en el Sahara ocupado por Marruecos). Este censo para el referéndum de autodeterminación plantea dudas políticas y jurídicas.

Políticamente, el censo establecido por el Plan Baker II parece resultar favorable a Marruecos. Este censo se compone de tres listas que se interseccionan entre sí: la del censo de la ONU, la de residentes en el Sahara ocupado desde 1999 y la de refugiados. La primera lista se confeccionó en dos fases. En la primera, culminada en julio de 1999, la ONU estableció un censo de 84.251 votantes (seleccionados entre 147,229 aspirantes), de los cuales un 54.9\% $(46,254)$ fueron candidatos presentados por Marruecos y que viven en Marruecos o en el territorio ocupado, un $40.1 \%(33,785)$ fueron candidatos presentados por el Frente Polisario y que viven en los territorios liberados o en los campamentos de refugiados y un 5\% $(4,213)$ se presentó en Mauritania. A pesar de que la mayor parte de los seleccionados se presentó en el territorio controlado por Marruecos, también es cierto que la inmensa mayoría de los rechazados fueron candidatos presentados por Marruecos. ${ }^{81} \mathrm{El}$ censo culminó en diciembre de 1999 tras la identificación de las llamadas "tribus disputadas". De los 51,220 candidatos entrevistados, las Comisiones de Identificación declararon como votantes sólo a 2,135, de los cuales casi todos viven en Marruecos o en el Sahara ocupado. Esto arroja una cifra total de 198,469 candidatos entrevistados con 86,386 personas declaradas como saharauis ${ }^{82}$ y 112,083 descalificados. A su vez, de entre los de-

81 En aquel momento, el entonces ministro del Interior marroquí y gerente del asunto del Sahara, Driss Basri, declaró a El País (16-VII-1999, p. 7) que "la lista de votantes que ha recibido [la de los 84.251 electores] es un 'gran éxito' para Marruecos, porque la mayoría de los seleccionados fueron presentados por su país y no por el Frente Polisario, y residen en él o en la ex colonia española... de ahí que se atreva a dar el referéndum por ganado y lo describa como 'una mera formalidad'. 'Esta lista de la ONU hace añicos el mito de que el pueblo saharaui está refugiado en la región de Tinduf y que el antiguo Sahara español está poblado por colonos enviados por Marruecos', afirmó Basri visiblemente satisfecho". La noticia, firmada por Ignacio Cembrero, sigue diciendo que "el titular de Interior confía, no obstante, en incrementar su avance. El 15 de junio, la Minurso empezó a examinar a un último grupo de 65.000 personas pertenecientes a tres tribus que, según el Frente Polisario, no son saharauis. 'Por poco que un puñado de ellos sean finalmente aceptados, la ventaja de Marruecos será aún más holgada', vaticinó Basri... 'el Frente Polisario ya ha tocado techo y no puede crecer más en número de electores potenciales"”.

82 Los datos definitivos del censo en el informe del SG S/2000/131, de 17 de febrero (parágrafo 6). 
clarados como saharauis (86,386), unos 48,389 viven en Marruecos o en el territorio controlado por Marruecos.

Los cálculos políticos dependen de la intersección entre las tres listas que concurrirían al eventual referéndum de autodeterminación porque hay saharauis reconocidos como votantes (primera lista) que también son refugiados (tercera lista) y saharauis reconocidos como votantes (primera lista) que también son residentes en el Sahara controlado por Marruecos (segunda lista). Si tomamos en cuenta las dos listas conocidas observaremos que entre los 151,696 "residentes" en el territorio ocupado del Sahara se encuentran a unos 48,000 saharauis reconocidos como tales por la ONU, de lo que se deduce que hay unos 103,000 colonos marroquíes que podrían votar. Por ello, a salvo de lo que resulte de la lista de refugiados nos encontraríamos con una cifra total de unos 189,000 individuos de los cuales 86,000 son saharauis (un 45\%) y unos 103,000 marroquíes (un $55 \%$ ). Si recordamos que el número total de personas presentadas en las Comisiones de Identificación fue de unos 198,000 y que Marruecos bloqueó el referéndum, porque de ese total la ONU sólo estimó como votantes a 86,000, constataremos que el Plan Baker II da a Marruecos justamente el censo que Marruecos quiso establecer. Parece, sin embargo, que Marruecos teme (así se desprende de su escrito de respuesta al plan) que en la lista de refugiados haya muchas personas que no están inscritas en el censo de la ONU de 1999 de forma tal que la lista de refugiados (no conocida) se convertiría en el auténtico fiel de la balanza. Esto explica la insistencia de Omar Hilal, embajador de Marruecos ante la sede la Naciones Unidas, en Ginebra, ante el Alto Comisionado de Naciones Unidas para los refugiados (ACNUR-HCR) para que proceda a un "censo y registro" de los refugiados más exhaustivo que la "lista" actualmente en vigor. La presión marroquí condujo a que el Comité Ejecutivo de ACNUR aprobase el 3 de octubre de 2003 una resolución, reconociendo "la importancia de los sistemas eficaces y precoces de registro y censo en tanto que instrumentos de protección y medios para cuantificar y evaluar las necesidades de alimentación y de distribución de la ayuda humanitaria".

Jurídicamente, la inclusión como votantes de un referéndum de autodeterminación de los "residentes" en un territorio resulta de muy dudosa legalidad. Es importante advertir que Argelia no ha puesto objeciones en su respuesta al plan a este punto crucial. Igualmente Marruecos tampoco ha objetado esta cláusula. Sin embargo se pueden hacer varias objeciones 
a la misma. Por un lado, hay que recordar que el TIJ estableció que en este referéndum deben participar las poblaciones "originarias" y no los meros "residentes". ${ }^{83} \mathrm{La}$ determinación de las poblaciones originarias, precisamente la llevaron a cabo las propias Naciones Unidas que oficialmente proclamaron en enero de 2000 el censo del "pueblo saharaui" que debía ejercer la autodeterminación. La ONU no puede ahora sostener lo contrario de lo que ella misma ha hecho. Pero además, por otro lado, el "nuevo" censo que propone James Baker vulnera una disposición fundamental del derecho internacional. El cuarto convenio de Ginebra, de 12 de agosto de 1949, relativo a la protección debida a las personas civiles en tiempos de guerra, establece en su artículo 49 un mandato muy claro: "la potencia ocupante no podrá deportar o transferir parte de su propia población civil al territorio que ocupa". Finalmente, y por si ello fuera poco, en la medida en la que esos "residentes" sean marroquíes venidos con la "marcha verde", el Consejo de Seguridad estaría desdiciéndose de lo que ordenó en su momento, ${ }^{84}$ a saber, la retirada del territorio de todos los participantes en la marcha verde. Es obvio que la propuesta de Baker pretende incluir en el "nuevo censo" a unos colonos que fueron transferidos por Marruecos al territorio que ocupa. No parece admisible afirmar como hace Marruecos en su respuesta a este punto del plan que ello es "justo" y "conforme con la práctica democrática", porque en cualquier práctica democrática y en cualquier ordenamiento jurídico hay una distinción esencial entre los "ciudadanos" y los demás "residentes" que no tienen ciudadanía. En ningún Estado, por democrático que sea, los residentes extranjeros no ciudadanos eligen una asamblea constituyente o el parlamento ordinario.

Estos aspectos del plan, por más que sean de dudosa legalidad internacional, parece que difícilmente podrán ser removidos. Del texto de la resolución 1495 se desprende que las negociaciones entre las partes y con la ONU deben encaminarse a la "aceptación" del texto ya elaborado y a su "aplicación", pues como el SG subrayó ${ }^{5}$ lo que quiere es abrir un nuevo proceso interminable de negocios. Por tanto, no parece que se abra la puerta a negociaciones dirigidas a modificar el texto del plan. Esto

83 ICJ Reports 1975, parágrafos 161 y 162. Por esta razón, los colonos españoles no podrían votar en el eventual referéndum.

84 S/RES/380 (1975).

85 "Mi enviado personal y yo consideramos, por el contrario, que las partes deberían aceptar el plan tal como se ha propuesto" (parágrafo 56, S/2003/565). 
que, por un lado, hace difícil corregir los puntos del plan de cuestionable legalidad internacional, también hace difícil que Marruecos pueda intentar "renegociar" el plan para que el mismo mantenga los puntos más favorables (título jurídico de la ocupación, el censo y el control del territorio) eliminando aspectos más "incómodos" (como el del periodo transitorio dominado por una autoridad del Sahara Occidental probablemente independentista). Las negociaciones que pide la resolución onusiana, por tanto, deben ir dirigidas, primero, a ver si las partes aceptan el plan, y después a "completar" el mismo con el fin de hacerlo aplicable, pero sin modificar su texto. Por ello, la negativa de Marruecos a aceptar un plan considerado "óptimo" por el Consejo de Seguridad tendría un altísimo coste político, aunque sea posible jurídicamente.

\section{EL RECHAZO MARROQUÍ AL PLAN BAKER II}

1. El Plan Baker II resulta una solución jurídica que, como se ha argumentado, parece claramente favorable a Marruecos: no sólo concede a Marruecos más incluso de lo que la legalidad internacional permitiría (admisión de los colonos marroquíes en el censo del referéndum de autodeterminación), sino que lo hace mediante la vía que el propio Marruecos propuso (descentralización y democracia). Esta solución jurídica ha recibido el apoyo firme y constante del SG de Naciones Unidas y de su enviado especial, James Baker, que lo califican como "un enfoque justo y equilibrado" 86 y como "la mejor solución política para el conflicto". ${ }^{87}$ La aprobación de la resolución 1495 supuso una de las mayores derrotas diplomáticas marroquíes de los últimos años pues no puede ignorarse que el Consejo de Seguridad decidió apoyar como "solución política óptima" y por unanimidad, justo lo que Marruecos consideró previamente como totalmente rechazable, y el Frente Polisario había aceptado tras una inicial oposición. El Consejo de Seguridad después de dar su apoyo unánime al Plan Baker II, conminó a Marruecos a aceptar el plan. Marruecos, derrotado jurídicamente, declinó dar su aceptación a dicho plan, primero con dilaciones y luego con condiciones imposibles. En el lapso de tiempo que le fue concedido para dar su respuesta, Marruecos emprendió su enésima ofensiva política para intentar justificar posterior-

87 S/2004/325, de 23 de abril de 2004 (parágrafo 38). 
mente su rechazo. Esta ofensiva se articuló en varios frentes: el "frente humanitario", el "frente tribal" y el "frente terrorista".

En primer lugar, Marruecos ha atacado en el "frente humanitario". Por más que al día de hoy en el Sahara ocupado y en Marruecos se vulneren los derechos humanos, Marruecos se ha servido de la "puesta en escena" de un "informe" sobre los prisioneros marroquíes elaborado por dos miembros de "France Libertés" para atacar al Frente Polisario. ${ }^{88}$ Así ha ocurrido en los debates de la Cuarta Comisión (descolonización) de la Asamblea General de la ONU de 2003. No importa que dicho informe esté plagado de groseras mentiras e inexactitudes puestas de manifiesto en el desmentido oficial del Frente Polisario a las acusaciones vertidas en el mismo: ${ }^{89}$ con fines de propaganda, el informe facilita la tarea de sembrar dudas sobre la imagen del Frente Polisario. Como he argumentado en otro lugar, este informe no sólo contiene inexactitudes jurídicas de bulto, exageraciones y afirmaciones increíbles, sino que apareció, precisamente, cuatro días después de la aprobación de la resolución 1495, cuando Marruecos se hallaba diplomáticamente aislado. ${ }^{90} \mathrm{El}$ informe permitía así un contraataque, siquiera fuera temporal.

El segundo frente es el "tribal". En su primera respuesta (2003) al Plan Baker II ,Marruecos ya había lanzado la acusación de que el proceso de elección del legislativo y el ejecutivo autonómicos previstos en el Plan Baker II no tomaba en cuenta la "estructura tribal" de la población del territorio. ${ }^{91}$ Marruecos dibujaba un escenario de inestabilidad por luchas tribales desencadenadas en el periodo de autonomía previsto en el Plan Baker II. El Consejo de Seguridad, sin embargo, no tomó en cuenta esos argumentos. Después del visto bueno dado al Plan Baker II por el Consejo de Seguridad en la resolución 1495, Marruecos ha vuelto a reiterar estas alegaciones. Con tal fin, ha enviado a varios Estados miembros del Consejo de Seguridad (Francia, España, Alemania, Reino Unido, México, Chile) y a otros Estados (Italia) una delegación de saharauis afectos a Marruecos que, además de pretender ser "representantes" de la

88 El informe se puede consultar en Internet en: $h t t p: / / w w w$.france-libertes.fr/actu/actudhci/Informe_Tindouf.pdf.

89 La respuesta del Frente Polisario frente a las acusaciones vertidas se puede consultar en: http://www.spsrasd.info/sps-s210903.html.

90 Me remito a mi trabajo "La mentira humanitaria y la verdad política (crítica del informe Karmous-Dubuisson)", publicado en: http://www.wsahara.net/03/menthumpol.html.

91 Parágrafo 16 de las "Observaciones del Reino de Marruecos...". 
"mayoría" de la población saharaui (sin que haya ningún proceso electoral que avale esa afirmación) pretenden llamar la atención sobre los problemas que podría provocar el Plan Baker II. Los argumentos se hallan recogidos en un "memorándum" donde abundan las inexactitudes históricas y jurídicas. ${ }^{92}$ Ocurre que el argumento del miedo tomando como excusa el tribalismo es un argumento de extraordinaria debilidad por varias razones. En primer lugar, la población saharaui no es la única de la región (ni del continente africano) que tiene una estructura tribal: Marruecos, Argelia, Mauritania... también tienen una estructura tribal y no parece que en este momento haya en estos países guerras civiles tribales (la crisis de la Cabilia no es, estrictamente hablando, tribal). En segundo lugar, si la población saharaui tiene una estructura tribal no se ve por qué en el Sahara ocupado por Marruecos no hay guerras entre las diferentes tribus a pesar de que ningún proceso electoral marroquí se vertebra en torno a los factores tribales (ni la elección al parlamento ni las elecciones municipales). No se ve por qué si ahora no hay conflictos tribales en los procesos electorales en curso en el Sahara ocupado, sí que los iba a haber en un Sahara autónomo o independiente. En tercer lugar, llama también la atención que entre la población saharaui de la RASD tampoco haya luchas tribales, a pesar de esa "estructura tribal". El único conflicto interno con connotaciones tribales se produjo hace 15 años (en 1988) sin que se hayan vuelto a producir problemas de esa naturaleza. En definitiva, no se ve por qué va a haber luchas tribales donde ahora no las hay y donde hay pocas posibilidades de que las haya en un nuevo Estado con un fuerte sentimiento nacionalista y, por ende, supratribal.

Finalmente, en tercer lugar, Marruecos emprendió una ofensiva oficiosa en el frente "terrorista", justo cuando se terminaba el último plazo (abril 2004) para dar su respuesta a la petición de aceptación al Plan Baker II. A través de un periodista cercano al régimen (el corresponsal de Agency Press en Rabat), se lanzó una "información” que vinculaba al Frente Polisario con las actividades terroristas de Al Qaeda. A pesar de que esta "información" fue formalmente desmentida por la agencia oficial de prensa de la RASD, ${ }^{93}$ por la asociación francesa de amigos de la

92 "Memorándum relativo a la ultima ( $\mathrm{sic}$ ) propuesta del señor James Baker, enviado personal del secretario general, acerca del Sahara marroqui (sic)". El texto de este memorándum no está publicado en medios de comunicación, que yo sepa.

93 El gobierno saharaui "extrañado" por el alineamiento de un artículo de la agencia de prensa AP del lado de la propaganda marroquí [http://www.spsrasd.info/sps-s080204.html\#2]. 
República Árabe Saharaui Democrática ${ }^{94}$ y por el ministro delegado para Europa de la RASD (Mohamed Sidati), ${ }^{95}$ Marruecos ha seguido impulsando oficiosamente esta calumnia ${ }^{96}$ a pesar de que incluso entraba en contradicción con otras falsas imputaciones hechas por la propaganda marroquí contra el Frente Polisario. Así, en primer lugar, es contradictorio decir oficiosamente (nunca oficialmente ante la ONU) que el Frente Polisario es un conjunto de "mercenarios" controlados por el ejército argelino y, por otro lado, decir que ese mismo Frente se halla en tratos con el Grupo Salafista de Predicación y Combate (GSPC), grupo terrorista integrista que está siendo duramente combatido, precisamente, por el ejército argelino. En segundo lugar, es contradictorio decir que el Frente Polisario está controlado por jóvenes "islamistas" que han sido contaminados por esta ideología en las universidades argelinas y, por otro lado, denunciar la "deportación" de los jóvenes saharauis a Cuba para ser adoctrinados en la ideología del marxismo-leninismo (atea, como es sabido). Y, en tercer lugar, es contradictorio atribuir un carácter "terrorista" al Frente Polisario cuando ha llevado a cabo actividades militares amparándose en el derecho de la guerra (así, por ejemplo, los prisioneros de guerra marroquíes están debidamente registrados y son visitados por el Comité Internacional de la Cruz Roja).

2. Como se ha dicho, aunque Marruecos había rechazado el plan antes de su aprobación por el Consejo de Seguridad, éste, tras prestarle su apoyo unánime conminó a ese país para que lo aceptase. Marruecos pidió tiempo "para reflexión y consultas antes de dar una respuesta definitiva". Inicialmente se le concedió un tiempo hasta finales de $2003,{ }^{97}$ pero tras una reunión de James Baker con la delegación marroquí el 23 de diciembre de 2003, se acordó dar a Marruecos un nuevo plazo, hasta abril, "a fin de poder realizar nuevas consultas con Marruecos respecto de su res-

95 Communiqué de presse (6-IV-2004) de l'Association des Amis de la République Arabe Sahraouie Démocratique [http://arso.org.site.voila.fr/AARASD060404.html].

96 Déclaration de Mohamed Sidati, ministre délégué pour l'Europe, 19-04-04 [http://www.arso.org/Sidati190404.htm].

96 Así, en La Gazette du Maroc (núm. 361, de 29-III-2004: "Alliance incestueuse: Al Qaïda-Polisario"); en el despacho de la agencia oficial de prensa marroquí (MAP) de 1-IV-2004 ("Sécurité au Maghreb: Des experts soulignent à Genève la 'menace' d'un Polisario recyclé dans le 'trafic d'armes' et le 'terrorisme'”); en Tel Quel (núm. 121: “Terrorisme: Al Qaïda au Sahara?"); en La Vie Économique (16-IV-2004: "L’inquiétante connexion Polisario-Al Qaïda").

97 S/2003/1016 (parágrafo 28). 
puesta definitiva al Plan de Paz". ${ }^{98}$ Finalmente, tras este nuevo plazo no le fue posible ya a Marruecos retrasar más su respuesta.

En su respuesta, ${ }^{99}$ Marruecos realiza varias declaraciones que constituyen una rebeldía notoria respecto al derecho internacional vigente sobre el conflicto, además de ir contra los propios actos de Marruecos en el pasado.

Así, en primer lugar, Marruecos en su respuesta declara que "adoptó una posición basada en el significado que se daba a la solución política, que siempre se había presentado como una solución de transacción consistente en una forma de autonomía en el marco de la soberanía marroquí". Es evidente que esto resulta jurídicamente insostenible pues si la ONU no reconoce la "soberanía marroquí" sobre el territorio, difícilmente puede reconocer una "autonomía en el marco de la soberanía marroquí".

En segundo lugar, Marruecos declara que "esta solución política basada en la autonomía será necesariamente definitiva" y que "el carácter definitivo de la solución de autonomía no es negociable para el reino". Ahora bien, como recuerda el propio SG, el atribuir un carácter "definitivo" a esa "autonomía" establecida sin haber dado al pueblo saharaui la opción de independencia es algo que "tiene consecuencias negativas para el ejercicio de la libre determinación, contemplado en la resolución 1429 (2002)". Dicho más claro: esta forma de entender como "definitiva" una "autonomía" sin haber dado opción a la independencia vulnera claramente el derecho.

En tercer lugar, Marruecos afirma que "está fuera de lugar que Marruecos entable negociaciones con quien sea acerca de su soberanía e integridad territorial". Esto puede ser cierto por lo que respecta a los territorios que la ONU reconoce como parte de su "integridad territorial" y sometidos a su "soberanía". Pero en relación al Sahara Occidental estamos ante una afirmación in vacuo pues el derecho internacional ni reconoce "soberanía" a Marruecos sobre el Sahara Occidental ni lo considera parte de la "integridad territorial" marroquí.

3. Esto nos suscita, en primer lugar, la pregunta del por qué de este rechazo. Las explicaciones de este hecho se encuentran en factores inter-

99 Anexo I al informe S/72004/325 ["Respuesta del Reino de Marruecos a la propuesta del señor Baker titulada 'Plan de paz para la libre determinación del pueblo del Sahara Occidental'”]. 
nacionales, en factores internos marroquíes y en la propia evolución de la población saharaui afectada por el conflicto, sobre todo en los territorios ocupados.

A. La explicación internacional se movería en un plano estratégico y otro táctico.

Estratégicamente, la región del Magreb y del Mediterráneo Occidental parece conocer una redefinición para adecuarse a las alianzas globales planetarias: España ha apostado por una alianza estratégica con Estados Unidos de América en detrimento de su anterior posición acólita de Francia así como por un mayor acercamiento a Argelia, especialmente visible en la "crisis del perejil"; Argelia, sin abandonar sus antiguas relaciones con Rusia, está intentando un acercamiento a Francia y, sobre todo, a Estados Unidos de América; Marruecos quiere seguir manteniendo su tradicional alianza con Francia y con Estados Unidos de América a pesar de las divergencias entre ambas potencias; el Frente Polisario quiere proseguir en su política de acercamiento a España, Argelia y Estados Unidos de América. La ubicación de España y Estados Unidos de América en las mismas coordenadas internacionales, sumada a la aproximación argelina y saharaui a estas posiciones, ha redundado en un cambio sustancial de los criterios de Estados Unidos de América sobre la cuestión. Marruecos se ha visto así ante una tesitura especialmente delicada, ya que ha intentado mantener su privilegiada relación con Francia siendo, al mismo tiempo, aliado de Estados Unidos de América. La crisis de Iraq ha llevado la confrontación franco-estadounidense a un punto de tensión máxima. El conflicto del Sahara y la discusión ante el Consejo de Seguridad puso de manifiesto la verdad de las cosas: pese a que la negociación del acuerdo de libre comercio con Estados Unidos de América y la solución de la "crisis del perejil" fueron vistos con recelo en Francia como intentos de decantarse por Estados Unidos de América en detrimento de Francia, la realidad es que en el momento decisivo Marruecos se ha enfrentado a Estados Unidos de América apoyándose para ello en Francia. Esto en principio debiera conducir a un endurecimiento (más o menos intenso) de Estados Unidos de América respecto a Marruecos pues no parece que Estados Unidos de América quiera avalar una ganancia geoestratégica que fuese a ser aprovechada por su principal antagonista internacional, que en este momento es Francia.

Desde un punto de vista táctico, la aceptación del Frente Polisario (aparte de inducida por las presiones hispano-argelinas, como así confesó 
el representante del Frente Polisario en la ONU) se explicaría así ante la previsible postura de Marruecos. El Frente Polisario y Argelia calcularon que Marruecos se iba a oponer al plan, a pesar de ser tan favorable a las posiciones históricas marroquíes. Al calcular que Marruecos se opondría, consideraron que una respuesta afirmativa generaría varios beneficios: aislar a Marruecos, desnudar sus contradicciones (rechaza lo que antes pedía), ofrecer una salida a la población saharaui, desesperada en los campamentos de refugiados, y en el caso de que el plan se impusiera sobre la voluntad de las partes generar una imagen de "ganador" en la medida en que Marruecos al sobredimensionar sus expectativas aparecería como perdedor pese a obtenerlo casi todo.

B. Siendo los factores internacionales muy importantes, quizás sean más decisivos, en la posición marroquí de rechazo, los cambios en la política interior marroquí. El movimiento táctico argelino y saharaui de aceptación del mismo se podría haber basado en la presunción de que Marruecos se iba a oponer al plan, lo cual puede suscitar perplejidad, tratándose de un plan favorable a Marruecos. Sin embargo, los tiempos políticos han modificado las posiciones de partida de los actores. Tras la muerte de Hassán II, en Marruecos se ha desencadenado una crisis política, social y económica formidable. La miseria creciente, la emigración, el auge del islamismo, el cada vez mayor nivel de reivindicaciones de los bereberes, las exigencias de los sectores aperturistas y demócratas, todo ello ha puesto a la estructura tradicional del poder, al Majzén, a la defensiva.

La aplicación del Plan Baker II supondría la introducción, por primera vez, en un territorio controlado por Marruecos de un sistema totalmente democrático (siguiendo, por cierto, el modelo Estados Unidos de América) y federal con pleno reconocimiento de los derechos fundamentales. Justamente lo que Marruecos aparentemente ofrecía a cambio de la anexión. Si se aplicara el nuevo plan, el Majzén perdería su poder en el Sahara. Las competencias legislativas del Parlamento saharaui y el sistema judicial independiente previsto en el plan podrían dar lugar a la elaboración de una "legislación de la libertad" que sería el espejo en el que se mirarían los demócratas marroquíes. La comparación entre el Marruecos dominado por el Majzén y un Sahara democrático libre de las ataduras del Majzén produciría una reacción inevitable dentro de Marruecos en favor de la democratización y federalización del sistema, tantas veces prometida y tantas veces frustrada. No es casual, por tanto, que en su res- 
puesta al Plan Baker, Marruecos trate de "desactivar" estos tres puntos: descentralización (los Länder que prometía Hassán II son obsesivamente convertidos en "autoridad local" — como la de los ayuntamientos — en la respuesta marroquí), ${ }^{100}$ democracia (sometiendo al Poder Judicial saharaui a la férula del Poder Judicial marroquí) ${ }^{101}$ y derechos humanos (expresando incluso reservas ante el alcance que pudieran tener las libertades ideológica y de expresión). ${ }^{102}$

Si esto es así, cabría entender que Marruecos teme tres posibles escenarios futuros. Según el primero, la ampliación del censo a los colonos podría conducir a la anexión del territorio, pero este éxito "exterior" tendría un coste "interior", a saber, la ineludible democratización y federalización del sistema marroquí. Ante esta perspectiva, no es disparatado pensar que el Majzén marroquí crea preferible mantener el conflicto para preservar sus privilegios en Marruecos antes que conseguir una anexión que llevaría aparejada la pérdida de esos privilegios. El segundo escenario sería aquél en el que los propios colonos marroquíes votasen en favor de la independencia del territorio como único medio de conseguir vivir en un Estado democrático y próspero, precisamente como resultado de liberarse de las ataduras del Majzén. El tercer escenario sería que en lugar de "marroquinizarse" los saharauis de los territorios ocupados, los marroquíes se hayan ido "saharauizando", de suerte que el voto de los colonos no haría sino reforzar el voto independentista. Este proceso se ha advertido, no en los colonos llegados desde Marruecos, pero sí en sus descendientes, ya nacidos en el Sahara, como se puso de manifiesto en las revueltas de 1999 en El Aaiún. Parece obvio que Marruecos no se plantea un escenario en el que la población refugiada en Tinduf y los saharauis de las zonas ocupadas quieran integrarse en el reino.

C. A pesar de que existe una sensación de que la solución del conflicto está paralizada, lo cierto es que existen avances en el mismo. Uno de los más importantes ha sido la puesta en práctica de las primeras medidas de confianza entre las partes en conflicto. La Oficina del Alto Comisionado de las Naciones Unidas para los Refugiados y el Representante Especial para el Sahara Occidental del SG de la ONU han promovido con las partes la aplicación de medidas de fomento de la confianza. El

100 Parágrafos 3, 8, 9, 11, 12, 13, 14, 16, 18, 20 y 22 de las "Observaciones del Reino de Marruecos...”.

101 Parágrafos 12, 13 y 17 de las “Observaciones del Reino de Marruecos...”.

102 Parágrafo 8 de las "Observaciones del Reino de Marruecos...". 
propósito de esas medidas es facilitar los contactos personales entre los refugiados de los campamentos de la zona de Tinduf, en Argelia, y sus comunidades de origen en el Sahara Occidental. Ya en diciembre de 2003 se presentó una versión revisada del plan de acción del ACNUR a las partes para su examen final. A fines de enero y principios de febrero de 2004, las partes, así como Argelia en su calidad de país de asilo, comunicaron su aprobación del plan de acción revisado. Intercambio de visitas familiares. El primer intercambio de visitas familiares entre refugiados del Sahara Occidental que viven en los campamentos de la zona de Tinduf, en Argelia, y sus familiares en la ciudad de El Aaiún, dentro del territorio comenzó con éxito el 5 de marzo de 2004. En este primer intercambio, 21 refugiados fueron trasladados de Tinduf a El Aaiún en un vuelo de la Minurso, y 19 saharauis de El Aaiún a Tinduf en el vuelo de regreso. A pesar de ciertas quejas iniciales de ambas partes cuando se puso en marcha el programa, hasta la fecha los intercambios de visitas familiares no han experimentado tropiezos y han contado con la plena cooperación de las partes, así como de Argelia en su calidad de país de asilo. Además de a El Aaiún (capital del territorio), el programa de visitas se ha extendido a los originarios de las otras grandes poblaciones y regiones del Sahara: Smara, Bojador y Río de Oro (Dajla-Villa Cisneros) y Ausserd). Al 31 de marzo de 2004, más de 8,500 personas habían solicitado participar en el programa de intercambio, incluidas 2,850 del Territorio registradas en El Aaiún y 5,650 de los campamentos de refugiados de la zona de Tinduf. Se determinó que la mayoría de los solicitantes cumplían los criterios humanitarios y de vulnerabilidad establecidos por el ACNUR para esta actividad. Tal como se había previsto inicialmente, este programa tiene una duración de seis meses, con vuelos semanales, y periódicamente será objeto de examen y de ajuste, según proceda. ${ }^{103}$

La experiencia de los intercambios de visitas familiares ha sido un éxito rotundo desde el punto de vista logístico. Pero además, ha tenido un profundo significado político. En efecto, Marruecos ha intentado desacreditar a los refugiados saharauis en Tinduf, agrupados en el Frente Polisario, sosteniendo que no eran "refugiados" sino "secuestrados" en manos de unos "mercenarios". Precisamente por eso, Marruecos introdujo una cláusula en el programa según la cual aquellos saharauis provinientes de Tinduf que deseasen quedarse en el territorio controlado por 
Marruecos tendrían plena posibilidad de hacerlo. En el momento de escribir estas líneas es significativo que después de efectuarse un intercambio de miles de personas, sólo decidió quedarse en el territorio controlado por Marruecos una mujer y su hija mayor. Debe advertirse que la mujer dio a luz en un hospital de Villa Cisneros, precisamente mientras estaba visitando a sus familiares. De esta forma, aunque las medidas de confianza tienen un contenido exclusivamente humanitario, constituyen un indicio político que resulta poco favorable para Marruecos, porque ha puesto de manifiesto la falsedad de las imputaciones marroquíes contra el Frente Polisario, acusando a éste de "secuestrar" a la población civil.

\section{EL REFORZAMIENTO DEL DERECHO SAHARAUI Y EL NUEVO INTENTO MARROQUÍ DE ELUDIR EL DERECHO INTERNACIONAL MEDIANTE UN NUEVO “ACUERDO POLÍTICO” CUATRIPARTITO}

1. El rechazo de Marruecos al Plan Baker II después de haber sido avalado por el Consejo de Seguridad (que se suma al rechazo expresado antes de que el consejo lo avalase en su resolución 1495) ha sido implícitamente desautorizado. En efecto, resulta extraordinariamente significativo que, del mismo modo que la resolución 1495 avaló el Plan Baker II a pesar de la oposición al mismo de Marruecos, ahora el Consejo de Seguridad vuelva a reiterar su aval al plan y ello con términos inequívocamente contrarios a las pretensiones marroquíes. La resolución 1541 no sólo no acoge ninguna de las reservas de Marruecos, sino que tanto en su preámbulo como en su articulado la desautoriza tajantemente, aun cuando de forma implícita. En su preámbulo, la resolución 1541 dice que el Consejo de Seguridad apoya, sí, una "solución política" como pide Marruecos, pero precisa que la misma debe ser "justa" y permitir "el derecho a la autodeterminación del pueblo del Sahara Occidental en el marco de las disposiciones conformes con los fines y principios enunciados en la Carta de las Naciones Unidas". Por su parte, en el párrafo primero de la parte dispositiva, la resolución "reafirma su apoyo al Plan de Paz para la autodeterminación del pueblo del Sahara Occidental, que constituye una solución política óptima basada en un acuerdo entre las dos partes". De esta forma, el consejo rechaza las objeciones de Marruecos al Plan Baker II, a saber, que el plan no se basa en la "soberanía" marroquí sobre el territorio, que la autonomía debería ser definitiva y que el plan no debiera poner en cuestión la "integridad territorial" de Marruecos. El Con- 
sejo de Seguridad, al reiterar el derecho de autodeterminación del pueblo saharaui, en primer lugar, confirma que el Sahara Occidental es una colonia y, por tanto, no es territorio de "soberanía" ni forma parte de la "integridad territorial" de Marruecos. Además, en segundo lugar, al rechazar que la autonomía establecida provisionalmente en el plan deba ser definitiva, confirma que el estatuto definitivo del territorio debe ser decidido por el pueblo colonizado y tiene que hacerlo mediante un referéndum en el que se incluya la opción de la independencia.

2. La resolución 1541, desde el punto de vista del derecho, es sumamente negativa para Marruecos porque le cierra la puerta, más aún si cabe, a sus pretensiones. La situación no es nueva. Era muy similar en 1975 y Marruecos ha pretendido eludirla como en aquella ocasión.

En 1975, el dictamen del Tribunal Internacional de Justicia de 16 de octubre de 1975 supuso la desestimación de las pretensiones marroquíes al negar a este país ningún "derecho" sobre el territorio. Frente a aquella derrota jurídica, Marruecos llevó a cabo una audaz operación política: un acuerdo político tripartito en el que tres países (España, Marruecos y Mauritania) decidían el destino del territorio sin contar con la población del mismo. Es más, mientras la potencia administradora (España) daba garantías públicas a la población de que se iba a respetar su derecho a la autodeterminación, en secreto negoció un acuerdo que suponía su entrega a Marruecos y a Mauritania. Ese acuerdo tripartito, del que ya se ha hablado (supra III.2), no tiene ninguna virtualidad jurídica hoy en día, pero permitió una política de hechos consumados en contra del derecho dictado por el Tribunal Internacional de Justicia y las resoluciones de la Asamblea General de Naciones Unidas.

En 2004 hemos asistido a un intento parecido al de 1975, un nuevo acuerdo político dirigido a avalar la ocupación marroquí del territorio. Pero junto a muchas semejanzas, ha habido diferencias que lo han desbaratado. Las semejanzas son varias. En primer lugar, como en aquel entonces, este acuerdo político surge después de una derrota jurídica de Marruecos, en concreto, después de que la resolución 1541 cerrara cualquier posibilidad a las pretensiones anexionistas marroquíes. En segundo lugar, ahora como antes, este "acuerdo" se ha intentado fuera del marco de la ONU y sin contar con el pueblo saharaui, ya que la ONU sólo reconoce derechos al pueblo saharaui (el de autodeterminación) y no a Marruecos, y el Frente Polisario está considerado como una "parte del conflicto" ineludible. En tercer lugar, como en aquel tiempo, el gobierno 
español emitía confusas declaraciones, incluyendo algunas de apoyo al derecho de autodeterminación de los saharauis para tranquilizar a éstos, pero al mismo tiempo se hallaba en una negociación secreta que negaba tal derecho y entregaba el territorio a Marruecos. Pero ha habido algunas diferencias. Si en 1975 el acuerdo era tripartito (España, Marruecos, Mauritania) ahora se trata de un "gran acuerdo" cuatripartito (España, Francia, Marruecos, Argelia). Además, a diferencia de 1975, en 2004 uno de los socios (Argelia) ha rehúsado entrar en la operación. Y, finalmente, a diferencia de 1975, el Frente Polisario se halla mejor organizado, tiene cuadros mejor formados y con mucha más información que la que tenía en 1975.

El intento de llegar a un acuerdo secreto se ha abortado, al hacer público su rechazo por el ministro argelino de Asuntos Exteriores. El día 3 de mayo de 2004, el ministro español de Asuntos Exteriores hizo un viaje relámpago a Argel para entrevistarse con su colega argelino, Beljadem. En la rueda de prensa conjunta, el ministro español declaró que "Argelia y España tienen posiciones convergentes" sobre el conflicto del Sahara y que "España obrará, en el marco de Naciones Unidas, para animar el diálogo entre las partes afectadas". Sin embargo, la sorpresa saltó cuando en la misma rueda de prensa y en presencia del ministro español, su colega argelino Beljadem, al preguntarle por una posible mediación previa francesa en el conflicto, manifestó que "incluso si hay una reunión de tanteo sobre la cuestión del Sahara Occidental entre Francia, España y Marruecos sobre la cuestión del Sahara Occidental, Argelia no tomará parte en ella". La razón esgrimida por el ministro Beljadem es que "Argelia no es el tutor de ese país (la RASD)" insistiendo en que el problema "no se plantea entre nuestro país y la República Saharaui, sino entre ésta y Marruecos". ${ }^{104}$

Las declaraciones de Beljadem pusieron al desnudo los propósitos del ministro español Moratinos. Su viaje a Argel tenía como misión transmitir la aceptación española de la propuesta francesa de una reunión cuatripartita, sin los saharauis, para decidir sobre el destino del Sahara Occidental. Esa propuesta, que consideraba a los saharauis como un mero apéndice argelino, era secreta, ya que en ningún momento anterior la hicieron pública el presidente español o su ministro de exteriores. Las declaraciones de Beljadem haciendo pública la proposición de una reu- 
nión secreta cuatripartita, ilustran la enorme irritación ante la misma. Muy poco antes (el 1-V-2004), el ministro saharaui delegado para Europa, Mohamed Sidati, manifestó su rechazo ante unas insinuaciones del presidente español que dejaban entrever lo que dos días después iba a hacer público en Argel el ministro Beljadem ante su colega español. ${ }^{105}$

\section{PERSPECTIVAS}

Si, como parece, Marruecos está dispuesto a rechazar el Plan Baker II, incluso después de que la comunidad internacional lo haya considerado como "solución política óptima" en las resoluciones 1495 y 1541 del Consejo de Seguridad, ¿qué perspectivas tiene el conflicto? Todo parece indicar que Marruecos se va a atrever a incumplir estas resoluciones que, si bien no "imponen" el Plan Baker II (no lo han "aprobado" jurídicamente, aunque sí le han dado su visto bueno político), sí piden a las partes que "cooperen plenamente con las Naciones Unidas y entre ellas para aceptar y poner en práctica el Plan de Paz" (res. 1495) y que "cooperen plenamente con el secretario general y su enviado personal” (res. 1541). Marruecos se atreve a hacer caso omiso de la 1495 y la 1541 porque no es la primera vez que ha ignorado resoluciones del Consejo de Seguridad y nunca ha sufrido la mínima sanción por ello. Ya ha incumplido las resoluciones que le obligaban a "cooperar plenamente" en la puesta en práctica del Plan de Paz y los Acuerdos de Houston (resoluciones 658, 690, 725 y 1133 del Consejo de Seguridad, entre otras). Para ello buscará algún tipo de coartada. Las coartadas ideadas hasta ahora han resultado extremadamente burdas: así ha ocurrido con la fracasada coartada "humanitaria" (el Informe Karmous-Dubuisson, se demostró repleto de falsedades), con la no menos inane coartada tribal (el memorándum presentado ante varios Estados por la delegación de "representantes" de las "provincias del sur" con no menos inexactitudes ni siquiera se atrevieron

105 "El ministro delegado saharaui para Europa, y miembro del secretariado nacional, Mohammed Sidati, ha denunciado sin nombrarle la iniciativa del presidente del gobierno español Rodríguez Zapatero, "haciendo creer en la posibilidad de concluir de aquí a seis meses un acuerdo "entre las partes" sobre el asunto saharaui... Estimando que estas declaraciones no pueden ser percibidas más que como "un alineamiento anunciado del lado de las tesis del ocupante marroquí", Sidati afirma que las iniciativas y todos los esfuerzos con vistas a resolver el conflicto del Sahara Occidental deben irremediablemente reforzar las actuaciones de la comunidad internacional, y por lo tanto comprometerse en el seno de Naciones Unidas y no fuera de éstas" (despacho de la agencia oficial de noticias de la RASD, SPS, de 1o. de mayo de 2004: http://www.spsrasd.info/sps-s010504.html). 
a presentarlo en la ONU) o con la destinada a vender la imagen del Frente Polisario como "minoría" frente a los "representantes" de la mayoría de los saharauis (difícil de creer, ya que si los saharauis pro marroquíes son la "mayoría aplastante" no se ve cuál es el problema de organizar elecciones autonómicas y aun el referéndum). Ahora parece que los esfuerzos se concentran en la coartada "terrorista" no menos plena de contradicciones y falsedades. En cualquier caso, estas coartadas le pueden servir a Marruecos para intoxicar a quien no esté debidamente informado, o al menos "para salir del paso".

La pregunta es cómo va a reaccionar la comunidad internacional. El antecedente de las resoluciones incumplidas en el pasado no es alentador y constituye una razón adicional para poner fin a esta dinámica de rebelión ante el derecho internacional. Parece claro que el Consejo de Seguridad no puede desdecirse de la 1495 y de la 1541 que reitera la anterior. De momento, parece que Marruecos, además del apoyo francés, merced a la ayuda del lobby judío (después de la aprobación de la 1495, ha retomado sus contactos diplomáticos con Israel, a pesar de los crecientes atentados islamistas contra judíos que se producen en el país) ha conseguido que Estados Unidos de América afirme que no va a imponer ninguna solución contra el consentimiento de las partes. De esto se deduce que Marruecos se dispone a incumplir la 1495 y la 1541, repitiendo los mismos argumentos que el Consejo de Seguridad desechó al calificar al Plan Baker II como "solución política óptima” en dos ocasiones sucesivas.

La situación previsible, en consecuencia, será de bloqueo jurídico. Marruecos pretende que la ONU apruebe "jurídicamente" una "solución política" ¡consistente en ignorar el derecho internacional! Y esto es, sencillamente, imposible. Pero si la situación previsiblemente va a llegar a un punto de bloqueo "jurídico" (parece altamente improbable el reconocimiento de la anexión, y Marruecos se opone al Plan Baker II), lo previsible es que evolucione según los cambios "políticos" que se operen. Y aquí el panorama me parece altamente preocupante desde todos los puntos de vista, porque casi todas las posibles evoluciones políticas de la región parecen apuntar a una mayor inestabilidad política. La evolución política puede provenir del campo marroquí, de los países vecinos o del saharaui.

En el lado marroquí, la inestabilidad puede provenir del innegable descontento de la población saharaui que vive en los territorios ocupados, y que, ya en el pasado, ha protagonizado revueltas contra Marrue- 
cos. Pero también puede provenir de la evolución del propio Marruecos si continúa el actual inmovilismo del Majzén frente a las demandas de democratización o si continúan fortaleciéndose los movimientos islamistas.

Por parte de los países vecinos, la búsqueda de un nuevo acuerdo secreto (al modo del "gran acuerdo" cuatripartito que se ha pretendido) sin contar con los saharauis para avalar la anexión del territorio por Marruecos supone cerrar a éstos todas las salidas. Ya el Plan Baker II ha supuesto el máximo nivel de concesiones efectuado por el Frente Polisario. Pero si se cierra incluso la posibilidad de optar por la independencia en un medio plazo, la desesperación de los saharauis sólo les dejaría como única alternativa la guerra. Así se produciría la paradoja de que un "gran acuerdo" cuatripartito buscado con ansia de paz pueda ser el detonante de la guerra.

Por su parte, en el lado saharaui, una situación de bloqueo como la que se avecina hace, a mi juicio, cada vez más probable la vuelta a las armas ya sea por el Frente Polisario si tras el rechazo de Marruecos se acordase la retirada de la Minurso, ya fuera por unidades descontroladas. Los saharauis saben que su fuerza "política" residía, precisamente, en el enorme desgaste humano, social y económico que provocaban con su lucha militar. En un momento como el actual, de crisis en Marruecos, con la juventud desmotivada queriendo ir a Europa, la perspectiva de enviar a los jóvenes a morir en el Sahara puede incrementar para Marruecos el coste de la guerra. Muchos cálculos políticos se basan en la hipótesis de que los saharauis no van a volver a las armas, sobre todo después del fiasco producido, en el último momento, en enero de 2001, cuando tras anunciar la vuelta a la guerra, se suspendió el reinicio de las hostilidades por la fuerte presión argelina. Ahora bien, cuanto mayor es la espera, mayor es la desesperación de quienes, provistos de armas (mejores o peores), saben cómo utilizarlas con el máximo daño para Marruecos. Y hay algo más. No basta fiarlo todo a que Argelia pueda evitar esta vuelta a las armas. La clave, en este momento, puede estar en Mauritania: tanto si el Frente Polisario como unidades descontroladas vuelven a las armas, lo harán cubiertos en la retaguardia con los mauritanos. Una presión sobre Mauritania para impedir esto sólo provocaría más problemas: el Frente Polisario ya derrotó a Mauritania en 1979, y la presión sobre este país vecino sólo haría extender la guerra y el riesgo de una intervención marroquí en Mauritania para perseguir a los saharauis. El paso del tiempo 
aumenta las probabilidades de que pueda saltar la chispa que provoque un incendio de incalculables consecuencias. En definitiva, en mi opinión no es el Plan Baker II y sus hipotéticas luchas tribales, sino el enquistamiento de Rabat lo que creo que pone en serio peligro la estabilidad de la región.

\section{CONCLUSIONES}

Una vez constatado que el derecho por sí solo no se puede imponer y que la política de fuerza no es capaz de desvirtuar las exigencias del derecho, el nuevo Plan Baker II surge como una propuesta de compromiso entre la política y el derecho, entre la potencia con una mejor posición política de fuerza en tanto que controla la mayor parte del territorio (Marruecos) y otra parte con el título jurídico inesquivable del derecho a la autodeterminación, internacionalmente reconocido por todas las instancias onusianas (Frente Polisario). Este compromiso, claramente favorable a los deseos que Marruecos viene formulando desde hace 27 años, presenta aspectos problemáticos acerca del modo de entender el derecho de autodeterminación, reconociendo el mismo no sólo a las poblaciones "originarias" sino también a las "residentes". Sin embargo, el cambio de circunstancias de la política exterior y, sobre todo, interior marroquí hace que la solución propuesta se haga al coste que, precisamente Marruecos ofreció en el pasado: descentralización política y democracia. El miedo de la clase dirigente marroquí a perder sus privilegios ha conducido al rechazo de una propuesta que está en condiciones de otorgarle el triunfo diplomático tan largamente perseguido. No sólo esto, el rechazo marroquí del Plan Baker II conlleva el riesgo de dejar al conflicto sin una salida diplomática y pone en peligro la estabilidad de la región. 